
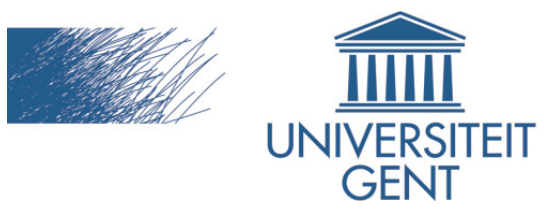

biblio.ugent.be

The UGent Institutional Repository is the electronic archiving and dissemination platform for all UGent research publications. Ghent University has implemented a mandate stipulating that all academic publications of UGent researchers should be deposited and archived in this repository. Except for items where current copyright restrictions apply, these papers are available in Open Access.

This item is the archived peer-reviewed author-version of:

Title: Spatio-temporal variability in remotely sensed land surface temperatue, and its relationship with physiographic variables in the Russian Altay Mountains

Authors: R. Van de Kerchove, S. Lhermitte, S. Veraverbeke, R. Goossens

In: International Journal of Applied Earth Observation and Geoinformation, vol. 20, 4-19, 2013

doi: 10.1016/j.jag.2011.09.007

To refer to or to cite this work, please use the citation to the published version:

R. Van de Kerchove, S. Lhermitte, S. Veraverbeke, R. Goossens (2013). Spatio-temporal variability in remotely sensed land surface temperatue, and its relationship with physiographic variables in the Russian Altay Mountains. International Journal of Applied Earth Observation and Geoinformation, 20, 4-19. 


\title{
Spatio-temporal variability in remotely sensed Land Surface Temperature, and its relationship with physiographic variables in the Russian Altay Mountains
}

\author{
R. Van De Kerchove ${ }^{\mathrm{a}, *}, \mathrm{~S}$. Lhermitte ${ }^{\mathrm{b}, \mathrm{c}}, \mathrm{S}$. Veraverbeke ${ }^{\mathrm{a}, \mathrm{d}}$, R. Goossens ${ }^{\mathrm{a}}$ \\ ${ }^{a}$ Department of Geography, Ghent University, Ghent, Belgium \\ ${ }^{b}$ Royal Netherlands Meteorological Institute (KNMI), De Bilt, The Netherlands \\ ${ }^{c}$ Centro de Estudios Avanzados en Zonas Aridas (CEAZA), Universidad de la Serena, \\ La Serena, Chile \\ ${ }^{d}$ Jet Propulsion Laboratory (JPL), California Institute of Technology, Pasadena (CA), \\ USA
}

\begin{abstract}
Spatio-temporal variability in energy fluxes at the earth's surface implies spatial and temporal changes in observed Land Surface Temperatures (LST). These fluxes are largely determined by variation in meteorological conditions, surface cover and soil characteristics. Consequently, a change in these parameters will be reflected in a different temporal LST behavior which can be observed by remotely sensed time series. Therefore, the objective of this paper is to perform a quantitative analysis on the parameters that determine this variability in LST to estimate the impact of changes in these parameters on the surface thermal regime. This study was conducted in the Russian Altay Mountains, an area characterized by strong gradients in meteorological conditions and surface cover. Spatio-temporal variability in LST was assessed by applying the Fast Fourier Transform (FFT) on eight year of MODIS Aqua LST time series, herein considering both day and night time series as well as the diurnal difference. This FFT method was chosen as it allows to discriminate significant periodics, and as such enables distinction between short-term weather components, and strong, climate related, periodic patterns. A quantitative analysis was based on multiple linear regression models between the calculated, significant Fourier components (i.e. the an-
\end{abstract}

\footnotetext{
*Corresponding author. Tel: +3292644646; Fax: +3292644985.

Email address: ruben.vandekerchove@ugent.be (R. Van De Kerchove)
} 
nual and average component) and five physiographic variables representing the regional variability in meteorological conditions and surface cover. Physiographic predictors were elevation, potential solar insolation, topographic convergence, vegetation cover and snow cover duration. Results illustrated the strong inverse relationship between averaged daytime and diurnal difference LST and snow duration, with a $R_{a d j}^{2}$ of 0.85 and 0.60 , respectively. On the other hand, nocturnal LST showed a strong connection with elevation and the amount of vegetation cover. Amplitudes of the annual harmonic experienced both for daytime and nighttime LST similar trends with the set of physiographic variables -with stronger relationships at night-. As such, topographic convergence was found to be the principal single predictor which demonstrated the importance of severe temperature inversions in the region. Furthermore, limited contribution of the physiographic predictors to the observed variation in the annual signal of the diurnal difference was retrieved, although a significant phase divergence was noticed between the majority of the study region and the perennial snowfields. Hence, this study gives valuable insights into the complexity of the spatio-temporal variability in LST, which can be used in future studies to estimate the ecosystems' response on changing climatic conditions.

Keywords: Land Surface Temperature (LST), Fast Fourier Transform (FFT), Russian Altay Mountains, spatio-temporal variability, physiographic predictors

\section{Introduction}

Land Surface Temperature (LST) plays an essential role in interactions and energy fluxes at the surface-atmosphere interface (Coll et al., 2005; Sobrino et al., 2003). In detail, spatio-temporal variability in LST reveals spatial and temporal changes in the state of the land surface which has been widely implemented in surface energy and water budget estimations (Bastiaanssen et al., 1998; Karnieli et al., 2010; Roerink et al., 2000b). In this context, LST has been used for a wide range of environmental studies ranging from forest fire risk assessment (Manzo-Delgado et al., 2009) to urban heat island (UHI) monitoring (Chen et al., 2006; Weng et al., 2004) and permafrost monitoring and modeling (Hachem et al., 2009; Langer et al., 2010; Westermann et al., 2010). All these studies rely on the sensitivity of LST to regional differences in surface albedo, the amount of water available 
for evaporative cooling, wind speed and surface roughness which regulate the strength of the sensible and latent heat fluxes (Oke, 1987). These regional differences are the result of influencing factors like vegetation cover, surface moisture, soil types, topography and the meteorological conditions (Sun and Pinker, 2004; Julien et al., 2006; Sandholt et al., 2002; Veraverbeke et al., in review). Consequently, LST plays a major role in the global change problematic and associated feedback effects: an initial increase in surface temperature might alter the influencing factors (e.g. accelerated snow melt, desertification, precipitation increase) which in turn can reinforce (positive feedback) or weaken (negative feedback) this increase. As such, in a changing climate, understanding and quantifying the spatio-temporal relationships between LST and its influencing factors is essential to make future predictions about global and regional temperature trends and coupled feedback effects (McCarthy et al., 2001).

Therefore, the development of quantitative models that describe this spatio-temporal relationships between LST and the environmental factors is crucial. Accordingly, obtaining these models was set as one of the main objectives, recently discussed on the International Workshop on the Retrieval and Use of Land Surface Temperature (NCDC, 2008). This is particularly important in mountain ranges, where temperatures have increased at a higher rate than the global mean during the 20th century (McCarthy et al., 2001).

A variety of environmental factors interact in mountain systems, resulting in complex spatio-temporal patterns of LST with large temperature gradients at small distances (Fu and Rich, 2002; Liu et al., 2006; Pouteau et al., 2011). These patterns and gradients often are the result of a strong topographic variation interacting with heterogeneous snow and land cover and variable meteorological conditions. Several studies have examined the thermal variability in mountain environments to assess the role of different parameters in these patterns and gradients. For example, Chuanyan et al. (2005) compared methods to model air temperature and demonstrated that topographic parameters such as elevation and slope have the biggest impact on the variability of local climate. Pouteau et al. (2011) highlighted the role of i) topographic convergence and potential insolation on local night frost risk, ii) elevation, latitude and the distance to salt lakes on regional temperatures. Snow cover also plays an important role in high mountains as it strongly affects the biotic and abiotic environment which is reflected in vegetation zonation and composition (Kozlowska and Rackowska, 2006). Snow influences plant formation by reducing the duration of the growing season, 
increasing soil moisture due to meltwater supply and altering subsurface temperatures (Kozlowska and Rackowska, 2006; Zhang, 2005). Additionally, an increase in snow cover extent increases surface albedo, which consequently reduces surface temperatures by decreasing the absorption of solar radiation (Bounoua et al., 2000; Kaufmann et al., 2003). Vegetation cover is another major player influencing surface temperatures as reported by Bounoua et al. (2000) who observed a cooling in summer temperatures caused by increased terrestrial vegetation within land covers. This effect was confirmed by Jeong et al. (2009) and Kaufmann et al. (2003). Furthermore, a slight warming during the winter was observed, primarily due to reduced albedo which is caused by partial masking of the snow surface by a denser canopy (Bounoua et al., 2000).

Accurate models that describe the spatio-temporal relationships between LST and the environmental factors require consequently an extensive spatiotemporal dataset of LST and factors as topography, snow, vegetation and insolation. Remote sensing data, due to its repetitive and synoptic nature, is very useful in this framework as they allow to integrate spatial and temporal information of LST, snow and vegetation cover with existent topographical information. Consequently, remote sensing data can provide a data set, that allows to model the spatio-temporal patterns between LST, snow cover and vegetation in an mountainous topography.

Different techniques have been previously reported to describe and quantify temporal characteristics of remote sensing time series (Coppin et al., 2004; Eastman and Fulk, 1993; Jönsson and Eklundh, 2002, 2004). Among the different methods, the Fast Fourier Transform (FFT) has been successfully applied by various authors to minimize noise and enhance relevant temporal features (Azzali and Menenti, 2000; Evans and Geerken, 2006; Jakubauskas et al., 2001; Lhermitte et al., 2008; Menenti et al., 1993; Olsson and Eklundh, 1994). The FFT decomposes time series into periodic signals in the frequency domain, which enables the analysis of signals with a specific frequency. Moreover, by selecting only those relevant harmonics, application of the FFT to time series comprising multiple years, retains only the general recurring signals. Applied to LST time series, this means that only long-term temperature features (climate) can be studied, whereas short-term variable temperature signals (weather) can be discarded. Consequently, the FFT is a suited technique to compare climate related temperature signals to datasets of explanatory variables.

Hence, the main objective of this paper is to perform a quantitative anal- 
ysis of the parameters determining the spatio-temporal variability in LST. Therefore, the relationship between the significant Fourier components derived from eight year of LST time series and five physiographic variables (elevation, snow cover, vegetation cover, topographic convergence and potential solar radiation) is examined by multiple regression analysis. This study was performed in the Russian Altay Mountains, an area characterized by strong spatio-temporal variability in the five physiographic variables (Klinge et al., 2003; Shaghedanova et al., 2002). At first, the study area and satellite data are presented in Section 2, while the Fourier transform is explained in Section 3. Results of the FFT, and relationships between components and physiographic variables are shown in Section 4 and discussed in Section 5.

\section{Study area and data}

\subsection{Study area}

The study area (Fig. 1) is situated in the Russian Altay Mountains, more detailed in the Kosh-Agach Region of the Altay Republic. This region has been subject to a tradition of geophysical, geographical and archaeological research (Gheyle, 2009; Goossens et al., 2009; Marchenko, 2007). The Russian Altay Mountains extend between approximately 48 an $53^{\circ} \mathrm{N}$ latitude and 83 and $92^{\circ} \mathrm{E}$ longitude with the Kosh-Agach Region situated at the meeting point of four countries: China, Kazakhstan, Mongolia and the Russian Federation.

\section{INSERT FIG.1 HERE}

The climate in the area is extremely continental with long, cold, dry winters and short summers (König and Rilke, 2004). The mean annual air temperatures (MAAT) at the Kosh-Agach meteorological station (Fig. 1) for 1966-75 was $-5,38^{\circ} \mathrm{C}$, while for $1985-94$ it was $-4,28^{\circ} \mathrm{C}$ (Fukui et al., 2007). Furthermore, strong temperature inversions occur in the former Pleistocene lake-systems of the Kuray and Chuya basins (Fig. 1) (Baker et al., 1993; Rudoy, 2002) and persist for several months (Klinge et al., 2003). In winter, the Siberian anticyclone blocks precipitation in the study area, except in the high mountains. Summers, however, are relatively warm and humid, with precipitation brought by the northwesterly flow. As a result, annual sums of precipitation vary from almost zero up to $1500 \mathrm{~mm}$, depending on altitude and exposure (Shaghedanova et al., 2002). 
The geomorphology of the region can be divided into several categories. Firstly, the high mountain ranges of Katun, Tabyn-Bogdo-Ola, North/South Chuya and Kuray contain several glaciated peaks, which are among the highest in Siberia ranging up to 4506 meters (Mount Belukha). Furthermore, ancient peneplanes (e.g. Ukok Plateau), together with intermontane depressions (e.g. Chuya and Kuray Steppe) give the landscape an open and vast character, typical for the study area (Shaghedanova et al., 2002).

The vegetation in the study area is characterized by a strong developed vertical zonality, further complicated by topography effects (forested northern and treeless southern slopes) and an increased aridity towards the south east (Shaghedanova et al., 2002). Desert steppe (mainly Stipa glareosa) is typical for the intermontane depressions (Chuya and Kuray steppe), as well as for the northwest of Mongolia (König and Rilke, 2004; Zhigulskaya, 2009). North-oriented slopes and more humid river valleys are dominated by woodlands; mainly Larix sibirica with sporadic occurrence of Pinus sibirica (Pelánková and Chytrý, 2009). These types mainly occur in the northwest of the study area. Above the tree line, which is situated between 2200 and $2500 \mathrm{~m}$, the subalpine zone accommodates shrublands and subalpine meadows, which shift towards alpine tundra in the alpine belt (Shaghedanova et al., 2002).

\subsection{Data \\ 2.2.1. Satellite data}

MODIS (Moderate Resolution Imaging Spectroradiometer) satellite time series were used in this study. The MODIS sensor is onboard the Terra and Aqua satellites and provides four daily observations at 1:30 AM (Aqua ascending node), 10:30 AM (Terra descending node), 1:30 PM (Aqua descending node) and 10:30 PM (Terra ascending node) local time (Justice et al., 2002). Eight year of Aqua MODIS daily LST scenes (MYD11A1, $1 \mathrm{~km}$ resolution, 1K accuracy (Coll et al., 2005; Wan, 2008), Aqua and Terra MODIS daily snow product (MYD10A1/MOD10A1, 500m resolution) and Aqua MODIS 16-day NDVI product (MYD13Q1, 250m resolution) covering the study area, were acquired for the period 01/10/2002-30/09/2010. Daytime LST, nighttime LST, snow cover, NDVI and associated Quality Assurance (QA) layers were subsequently extracted. Aqua LST images were chosen instead of scenes from the Terra platform, as Aqua record images around middle night and day. Eight year of data was acquired to enhance 
climate related signals and reduce the influence of interannual variability and short-term effects.

Preprocessing included subsetting, reprojecting and the removal of spurious data-points. These spurious data-points encompass pixels affected by clouds and other atmospheric disturbances, which were removed by using the enclosed quality assurance file. Several authors address the importance of such a thoroughly screening of cloud contaminated data points in time series analysis (Chen et al., 2004; Julien and Sobrino, 2010; Julien et al., 2006). Nevertheless, some spurious data points might still have entered the LST data set resulting in some erroneous values. Therefore, and to enable comparison with NDVI composites, daily LST time series were compiled into 16-day composites $\left(L S T_{d a y}\right.$ and $\left.L S T_{\text {night }}\right)$. Self-created composites, created by using a median value composite method, were preferred above standardized MODIS 16-day LST products due to the non-uniform sample-interval near year-end of the latter. These standardized products would affect the Fourier components as demonstrated by Scharlemann et al. (2008). The median composite method was preferred thanks to its independency towards outliers, as well as the representation of more naturally averaged temperatures. Contrary, the more used maximum value composite algorithm (Holben, 1986) would tend to overestimate temperatures. However, despite this chosen composite method, some errors were inevitably introduced by the impossibility to retrieve LST images during cloudy periods: By restricting the LST data to clear-sky days and cloud free nights, it is likely to underestimate winter temperatures (due to strong radiative cooling) and overestimate summer temperatures. Therefore, the accuracy of the interpreted relationships between Fourier components and physiographic variables will increase with decreasing number of cloud covered days. Finally, time series of the diurnal difference, $L S T_{\text {diff }}$, were created by subtracting the two compiled 16-day time series, $L S T_{d a y}$ and $L S T_{\text {night }}$. This diurnal temperature range was incorporated as it reflects the surface's buffering capacity (Verstraeten et al., 2006)

In addition, daily snow cover time series were calculated at $1 \mathrm{~km}$ resolution by resampling the Aqua snow cover product. Cloud contaminated data was as much as possible filled by the corresponding Terra product. Remaining data-gaps were filled by comparing the pixel status the day just before and after a cloudy period: if both pixels showed the same status, the cloud gaps were consequently given this status. If both pixels however showed opposite values (mainly during onset/offset periods), the cloudy pixels were assigned 
as snow covered. The latter was performed as the identification of thin snow layers $(<1 \mathrm{~cm})$ can be problematic (Hall and Riggs, 2007). This uncertainty is, however, diminished by the averaging effect and did not exceed seven days for a single year. Furthermore, 16-day, 1km NDVI time series were created by resampling the $250 \mathrm{~m}$ product. Additionally, zero values were assigned to snow covered pixels.

\subsubsection{Topographic data}

A digital terrain model was derived from SRTM (Shuttle Radar Topography Mission) elevation data (Jarvis et al., 2008; Reuter et al., 2007). This altitudinal data, with $90 \mathrm{~m}$ horizontal resolution and a vertical accuracy better than $9 \mathrm{~m}$, was resampled to and co-registered with the MODIS LST images in order to enable a statistical comparison.

\subsubsection{Physiographic predictors}

Based on the terrain model and satellite data, five different types of physiographic variables were calculated to examine their explanatory power in the observed spatial patterns of LST-metrics (Fig. 2). Firstly, elevation at $1 \mathrm{~km}$ resolution, was directly derived from the obtained digital elevation model. Secondly, among several potential snow metrics (Reed et al., 2009), the averaged yearly number of snow covered days, $n_{\text {snow }}$, was selected to represent the snow influence for every pixel in the study area. This particular metric was preferred because it does not require the calculation of an onset/offset value of the snow season, which demands subjective thresholds. Thirdly, the influence of vegetation on the LST-metrics was estimated by calculating the averaged yearly integrated NDVI (iNDVI) for every pixel. This iNDVI-metric was chosen among the several phenological metrics as it summarizes the complete growing season (Reed et al., 1994; Zhang et al., 2003). Fourthly, the influence of the topographical position was examined by calculating the Compound Topographic Index (CTI) (Gruber et al., 2009; Quinn et al., 1991). This index is a function of both the slope and the upstream contributing area and has been previously used as an index of cold air pooling (Holden et al., 2010; Pouteau et al., 2011). Low CTI values represent convex position positions like mountain crests, while high CTI values correspond to coves or hillslope bases. This is important as cold-air pooling or temperature inversions frequently happen in mountain environments, especially when large-scale winds are weak and skies are clear (Clements et al., 2003; Lundquist et al., 2008). These inversions exist when warm air overlies cooler 
air. This suppresses turbulence and effectively eliminates upward motion (Oke, 1987). Accordingly, cold air, which is the result of radiative cooling, is trapped by this effective lid which prevents the surface and air from heating up. Finally also the total yearly potential solar radiation (potSRAD) was calculated. This variable was obtained by adding up solar radiation, calculated at hourly interval by the method described by Kumar et al. (1997), for clear sky conditions. This method accounts for latitude, elevation, slope and aspect, sun angle and topographic shading.

\section{INSERT FIG.2 HERE}

\section{Methods}

\subsection{Fast Fourier Transform}

The three compiled LST time series $\left(L S T_{\text {day }}, L S T_{\text {night }}\right.$, and $\left.L S T_{\text {diff }}\right)$ were decomposed into the frequency domain by applying the Mixed Radix Fast Fourier Transform (FFT) (Singleton, 1969). This is a computationally fast variant of the Discrete Fourier Transform (DFT) which can be used to transform any equidistant discrete time series $f(t)$ into a set of scaled cosine waves (components) with unique amplitude $A_{k}$ and phase shift $\phi_{k}$ (Bracewell, 2000). As such the original time series can be reconstructed by:

$$
f(t)=A_{0}+\sum_{k=1}^{N-1} A_{k} \cos \left(2 \pi k t+\phi_{k}\right)
$$

Where $A_{0}$ is the arithmetic mean of the time series, $k$ is the frequency of the FFT component, $N$ is the number of samples in the time series and $t$ is an index representing the sample moment. This representation as a sum of unique cosine waves, allows to assess the contribution of each frequency to the original signal (Lhermitte et al., 2008).

Applying the FFT to the diurnal difference is similar to calculating the $F_{k}$-distance between the FFT components of the two time series. This $F_{k^{-}}$ distance is used as a similarity measure in a hierarchical image segmentation algorithm (Lhermitte et al., 2008). Mathematically, the $F_{k}$-distance corresponds to subtracting the two time series for each observation in the temporal sequence and using the amplitude of the resulting difference vector.

Relevant harmonics, used in the regression analysis, were selected by examining the temporal variability in the FFT components (Lhermitte et al., 
2008). This was achieved by means of calculating the contribution of each amplitude to the total amplitude variance (Jakubauskas et al., 2001).

\subsection{Regression analysis}

The relation between the five different physiographic predictor variables and the relevant Fourier-components was examined by applying multiple linear regressions models (i.e. an approach to model the relationship between a response variable $\mathrm{Y}$ and one or more predictors $\mathrm{X}$ ) with varying numbers of physiographic predictors as independent variables. Linear regression was preferred over quadratic equations, to prevent overfitting and promote analysis of the different relations. In addition, several authors addressed a linear relationship between temperature and one of the physiographic variables: e.g. elevation (Oke, 1987; Pouteau et al., 2011). Interaction terms were included to consider that the effect of a certain variable on the response might be influenced by the level of another variable. Furthermore, collinearity effects were examined by calculating the Spearman's rank order correlation coefficient (e.g. Hjort et al., 2010) which showed no sign of an unacceptably high level of intercorrelation between the independent variables (all values $<0.6$ ). Finally, also the potential problem with spatial autocorrelation (i.e. the fact that nearby LST-values are likely to be similar) was addressed by taking only one pixel every 10 kilometer. For every possible combination of variables, the adjusted $R_{a d j}^{2}$-value (coefficient of determination adjusted for the number of independent variables) and root mean square error (RMSE, estimator for the difference between observed and modelled values) were calculated to evaluate how well the particular variable-constellation explained the observed variance in the Fourier component.

\section{Results}

\subsection{FFT applied on LST time series}

Fig. 3a displays the regional averaged, single sided amplitude spectrum of the FFT analysis applied on all three LST time series. It is clear from the figure that significant peaks are found at $k=0, k=8$ and to lesser extent at $k=16$ and $k=24$. The frequency peak at $k=0$ corresponds to the average component, which represents the average LST-value throughout the observation period. Averaged over the study area, $A_{0, d a y}=3.5^{\circ} \mathrm{C}$, while at night, $A_{0, n i g h t}=-12.7^{\circ} \mathrm{C}$ with $A_{0, d i f f}=16.2^{\circ} \mathrm{C}$. However, Fig. 3a also demonstrates significant annual oscillations for all three time series as illustrated 
by the peak at the annual frequency $(k=8)$. These oscillations are related to the strong annual signal present in both $L S T_{d a y}$ and $L S T_{\text {night }}$ series and the seasonal difference between them. These strong annual signals reveal the extreme seasonality in these continental mountain ranges.

\section{INSERT FIG.3 HERE}

At night, the annual term explains $93.3 \pm 1.7 \%$ of the total amplitude variance, while during daytime the relative contribution is at $91.7 \pm 1.7 \%$. Other frequencies hardly exceed the $1 \%$ value (both day and night) which is reflected by their relatively low amplitudes in Fig. 3a. In contrast, the annual term for the diurnal difference only describes $63 \pm 12 \%$ of the total variance, which can be explained by the weaker annual signal present in these series and more pronounced higher frequencies. This is well demonstrated in Fig. $3 \mathrm{~b}$ which shows more short-term oscillations present in the original $L S T_{\text {diff }}$ time series of a random pixel in contrast to its original $L S T_{\text {day }}$ and $L S T_{\text {night }}$ series. Despite this, the different amplitude spectra confirmed the relevance of the annual term in the dataset which will therefore, together with the average term, be used for further analysis. These components are illustrated in Fig. 3b for the three LST time series of a random pixel. Consequently, Fig. 3b also demonstrates how LST composites can be represented by the combination of their average and annual Fourier component.

\subsection{Spatio-temporal variability in $L S T$}

Fig. 4 contains representations of the amplitudes of Fourier components $A_{0}$ and $A_{8}$ for all three temperature time series and reveals the spatiotemporal variability in LST. In addition, six pixels showing significant differences in average and annual LST signals are plotted in Fig. 5. These pixels are characteristic for certain subregions and as such enhance interpretation of the regional variability. Accordingly, Fig. 5 shows the thermal regime for pixels located in the dry steppe areas of Mongolia $(\star)$, Ukok $(\diamond)$ and Chuya $(\triangleleft)$ as well as for the Chuya River Plain ( $\nabla$, with moist grass) and Katun River Valley ( $\square$, covered with coniferous forests) and on the perennial snowfields around Mt. Belukha (o). The location of these pixels is illustrated in Fig. 4.

\section{INSERT FIG.4 AND FIG.5 HERE}


Spatial (Fig. 4) and temporal (Fig. 5) comparison of the mean term $\left(A_{0}\right)$ shows that during daytime steppe environments are characterized by an extreme thermal regime: hot summers, alternated with very cold winters, result in high $A_{0, d a y}$-values (Fig. 4a). In contrast, lower $A_{0, d a y}$-values are seen in the peneplanes and river valleys, mainly due to lower summer temperatures (Fig. 5a). Perennial snowfields exhibit the lowest average daily temperatures in the study area. At night however, the steppe areas show relatively lower averaged temperatures $\left(A_{0, \text { night }}\right)$ than for instance in the valleys of the

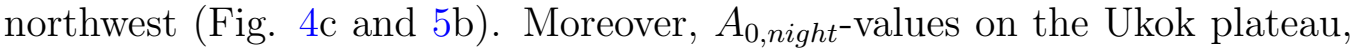
which can be seen as a high elevated steppe ecosystem, are among the lowest in the study area (Fig. 5b). Consequently, these steppe areas have the highest $A_{0, \text { diff }}$-values (around 25 degrees), while the river valleys experience less diurnal amplitude (Fig. 4e and 5c). Furthermore, annually averaged diurnal differences on high mountain ranges hardly exceed 10 degrees (Fig. 4e).

When considering annual amplitudes $\left(A_{8}\right)$, steppe areas generally show strong seasonality (Fig. 4b and d) characterized by low winter and high summer surface temperatures (Fig. 5a and b). In this context, it is striking that $A_{8, d a y}$-values in Mongolian steppes are much lower than in the Russian steppes (Fig. 4b). Secondly, the Chuya River Plain displays less daily seasonality than the steppe by which it is surrounded (Fig. 4b), although this difference disappears at night. Besides, low $A_{8, \text { day }}$ and $A_{8, \text { night }}$-values are encountered in the forests of the northwest and on the perennial snowfields. Annual amplitudes of the diurnal difference $\left(A_{8, d i f f}\right)$ reveal a contrast in seasonality between west and east. While relatively low values are typical for the west (with the lowest values observed on the perennial snowfields), larger annual variation in diurnal amplitude occurs in the east (Fig. 4f). Despite this general east-west difference, the lower steppe parts of Mongolia experienced relatively lower seasonality as showed in Fig. 4f and Fig. 5c. Largest seasonality appears in the Chuya and Kuray steppe, although significantly lower $A_{8, d i f f}$-values were retrieved in the Chuya River Plain (Fig. 4f and 5c). Additionally, these regional differences in seasonality of the diurnal difference were not only restricted to divergent amplitudes, but also in the timing of the maximum difference: for instance, it is shown in Fig. 5c that at Mt. Belukha, this maximum is observed during winter while in contrast, all other pixels showed their maximum in late spring/early summer. Regional variation in timing of this maximum can be assessed by calculating the phase of the annual harmonic $(k=8)$. Mathematically, this was achieved by calculating $\phi_{8}$ from Eq.(1) for which the results are presented in Fig. 6. 
Accordingly, Fig. 6 indicates that perennial snowfields showed less diurnal difference in summer than during winter which contrast with the overall behavior where the maximum difference is observed in the months May-July. The same representations can be made for phases of the annual signal present in $L S T_{\text {day }}$ and $L S T_{\text {night }}$, but these were not considered in this study due to little regional variation.

\section{INSERT FIG.6 HERE}

\subsection{Linear Regression Analysis}

The results of the multiple linear regression analysis are summarized in Table 1 and Fig. 7-9. Table 1 shows $R_{a d j}^{2}$ and RMSE-values for different combinations of descriptor variables, while the relationships between those variables and the amplitudes of the Fourier components $A_{0}$ and $A_{8}$, are graphically presented in Fig. 7 (day), Fig. 8 (night) and Fig. 9 (diurnal difference). Hardly any significant explanatory power could be observed for potSRAD, not as a single predictor, nor as an additional predictor variable (Table 1). Consequently, potSRAD was not included in Fig. 7-9. Nevertheless, with the four remaining predictor variables, between 74 and $87 \%$, and 36 and $66 \%$ of the variance in $A_{0}$ and $A_{8}$, respectively, was explained. In Fig. 7-9, $n_{\text {snow }}$, elevation and the CTI-index were chosen as independent variables as they explained most of the variance in the Fourier components. As a result, iNDVI was chosen as color coding.

\section{INSERT TABLE 1 HERE}

\section{INSERT FIG.7,8 AND 9 HERE}

\subsubsection{Day}

Table 1 and Fig. $7 \mathrm{~b}$ indicate a robust linear relationship between $A_{0, \text { day }}$ and the duration of the snow cover $\left(n_{\text {snow }}\right)$. Moreover, this relationship shows the highest $R_{a d j}^{2}(0.85)$ and lowest RMSE (2.02) for any single predictor variable. This relationship implies that an increase in the number of snow days relates to a linear decrease in the temporally averaged daily LST. Based on the slope of the regression fit, this means that if snow cover duration drops with twenty days, $A_{0, \text { day }}$ increases with $1.5^{\circ} \mathrm{C}$. Besides, it is demonstrated that high iNDVI values are restricted to those areas with snow days between 75 and 250 (Fig. 7b). As such, below and above these limits only low-stature 
vegetation persist. Elevation shows a weaker relationship with $A_{0, \text { day }}$ : the triangular shape indicates that at lower altitudes, a wide range of annual mean temperatures occur (Fig. 7a), partly due to the amount of vegetation cover (iNDVI) with lower/higher temperatures for high/low iNDVI-values, respectively. This interaction between vegetation cover and elevation on $A_{0, d a y}$ is demonstrated by a $R_{a d j}^{2}$-value which is higher than the sum of their individual $R_{a d j}^{2}$ (Table 1). Finally, also a slight positive connection between CTI and $A_{0, \text { day }}$ was retrieved, which demonstrates higher overall daily temperatures for the topographical basins (Fig. 7c).

For the regression analysis between the predictor variables and $A_{8, \text { day }}$, overall lower $R_{a d j}^{2}$-values are obtained than for $A_{0}$ (Table 1). This implies more complex relationships. Nevertheless, in general, $A_{8, \text { day }}$ decreases with elevation (Fig. 7d) and (Fig. 7e), and increases with CTI (Fig. 7f). As a single variable, CTI, was the best explanatory variable for the variance in $A_{8, d a y}$ with a $R_{a d j}^{2}$-value of 0.30 . Fig. $7 \mathrm{~d}$ also shows that, the general trend of a decreasing $A_{8, d a y}$ with increasing elevation did not hold true for high iNDVI values. Actually, Fig. 7d demonstrates that, temperatures at the same altitude show higher seasonality if there is a low-stature vegetation cover. Consequently, both variables experience strong interaction effects as illustrated in Table 1.

\subsubsection{Night}

In contrast to the robust linearity during daytime, Fig. 8b shows a more complicated relationship between $n_{\text {snow }}$ and $A_{0, \text { night }}$. A negative correlation is still present for low iNDVI-values, but disappeared for higher iNDVI-values. These pixels display independency to $n_{\text {snow }}$, and consequently other variables are required to predict trends in $A_{0, n i g h t}$. As such, elevation shows a higher correlation with $A_{0, n i g h t}$ than with $A_{0, \text { day }}$, indicating lower temperatures at night with increasing altitude (Fig. 8a). Moreover, CTI enhances this relationship to a $R_{a d j}^{2}$ of 0.66 , which is reflected in the small negative deviations in the elevation- $A_{0, \text { night }}$ diagram, corresponding to high CTI-values (Fig. 8a). This means that a pixel located in a topographical basin experiences overall lower night temperatures than pixels at the same elevation but with lower CTI-values. In contrast to daytime, iNDVI shows a strong, positive connection with $A_{0, \text { night }}$ which results in a $R_{a d j}^{2}$ of 0.47 .

For $A_{8, n i g h t}$, similar relationships are found as during daytime, with a higher $R_{a d j}^{2}$ for $A_{8, n i g h t}$ than $A_{8, d a y}$. This means that the annual amplitude at night also decreases at higher elevations (Fig. 8d), with more snow days 
(Fig. 8e) and increases in topographical basins (Fig. 8f). Once more, iNDVI and elevation show high dependency (Table 1). With the four principal explanatory variables together, a total $R_{a d j}^{2}$-value of 0.66 could be reached and a RMSE of less than $1^{\circ} \mathrm{C}$.

\subsubsection{Diurnal difference}

The major part $\left(R_{a d j}^{2}=0.60\right)$ of the observed variance in $A_{0, d i f f}$ could be attributed to changes in $n_{\text {snow. }}$. In fact, a longer snow cover induces overall lower $A_{0, d i f f}$-values (Fig. 9b). Moreover, strong interaction effects are observed between $n_{\text {snow }}$ and iNDVI, which result in relatively lower $A_{0, \text { diff }}$ values for pixels with high iNDVI. Overall, a multiple regression with the five variables shows a $R_{a d j}^{2}$ of 0.79 and a RMSE of $2.38^{\circ} \mathrm{C}$ (Table 1). In contrast, low explanatory power is observed between $A_{8, \text { diff }}$ and the set of physiographic predictors with a $R_{a d j}^{2}$ not reaching above 0.16 for a single predictor $\left(n_{\text {snow }}\right)$.

\section{Discussion}

\subsection{FFT applied on LST time series}

This study exploits the possibilities of the FFT to analyze spatio-temporal variability in remotely sensed LST. Hitherto, this method was mainly restricted to NDVI time series (Azzali and Menenti, 2000; Jakubauskas et al., 2001; Menenti et al., 1993; Moody and Johnson, 2001; Roerink et al., 2000a; Lhermitte et al., 2008) and few studies have applied the FFT to LST time series (Julien et al., 2006). However, in this study, the FFT has shown to be particularly useful to analyze LST time series. In fact, the ability of the method to discriminate fundamental periodics, enables distinction between short-term weather components, and strong, climate related, annual patterns. As such, it allows to extract mean and annual climatologies. These climatologies can then be linked to different environmental parameters to understand their role on the surface thermal regime. Moreover, this method has the advantage to allow fast comparison between geographical areas, as the Fourier components always express a certain periodicity (Lhermitte et al., 2008).

Assessment of the spatio-temporal variability of the Fourier components reflected the importance of the average $(k=0)$ and annual signal $(k=8)$ in the original time series. These periodics correspond to the relevant signals 
found by several authors in NDVI time series (Lhermitte et al., 2008; Loyarte et al., 2008), although this significance is closely related to the local climatic conditions, as well as typical vegetation phenologies. As such, the FFT method was succesfully applied to analyze spatial variability in average and annual climatologies. However, as stated by Wagenseil and Samimi (2006) and Lhermitte et al. (2011), care should be taken as the assumption of a perfect sinusoidal signal is often not satisfied for the complex shape of ecosystem dynamics and FFT analysis may therefore require higher frequency terms. Consequently, the annual climatology of time series determined by FFT analysis is an approximation which will be less suitable if more shape modulation of the annual signal is present in the time series. This is e.g. the case for barren pixels with a long lasting snow cover and a short but intense heating period. Furthermore, it is likely that in other areas, for example regions experiencing dry and wet seasons, bi-annual and even higher frequencies explain significant percentages of the temporal variability in the original time series. However, these pronounced higher order harmonics are absent in this particular LST-case, due to the extreme continentality of the study area, with long and cold winters and relatively hot summers.

Several limitations of the FFT-method has to be taken into account. The Fourier transform requires that signals, present in the data, are stationary, infinite in duration and the observation period is large enough to detect them. As such, the method, applied on eight year time series, implies the assumption of steady state temperatures in the Russian Altay Mountains during the observed eight years. This means that trends in averaged annual temperature, either an increase or decrease, as a change in the annual curve shape (extension/shortening of the seasons, shift in onset/offset of the growing season) cannot be detected by the method. Besides, also abrupt changes or discontinuities resulting from disturbance events are neglected (Verbesselt et al., 2010). Hence, this method fails to retrieve any signal changes, related to the global change problematic. This difficulty, was also encountered by Lhermitte et al. (2008), who proposed the application of the FFT on a yearly basis, and consequently consider the output differences between subsequent years. Despite these shortcomings, the main objective of this study is to perform a quantitative analysis on the parameters defining spatio-temporal variability in LST. Therefore, the influence of inter-annual variability, abrupt changes or weak trends are minor. 


\subsection{Relationships between Fourier components and physiographic variables}

The choice of appropriate physiographic variables is a subjective decision, which requires in-depth knowledge of the physical processes in the specific study area. Previous studies (Pouteau et al., 2011; Liu et al., 2006; Fu and Rich, 2002; Chuanyan et al., 2005; Bounoua et al., 2000; Kaufmann et al., 2003; Julien et al., 2006) made us test the influence of snow and vegetation cover and the local topography on observed differences in calculated Fourier components. Topography was further subdivided into three parameters (elevation, yearly potential solar radiation and the compound topographic index (CTI)) to assess the influence of different topographical attributes. The CTI-index was used to evaluate the effect of the strong air temperature inversions in the area on the surface temperature regime, while the potential solar radiation (potSRAD) was tested as an integrated effect of aspect and slope. Despite the use of these five variables, other parameters such as land cover and soil characteristics, might significantly contribute to the observed spatio-temporal variability in LST. However, due to the relative good fit of the regression models built with these five variables and possible intercorrelation between land cover and iNDVI as suggested by e.g. Reed et al. (1994), other parameters were neglected in our analysis.

Statistics from the multiple linear regression analysis illustrate the strong predictive capacity of the models, which can consequently be used for assessing the influence of the physiographic variables on the surface climatology. Moreover, these models allow prediction of the response in surface climatology on changes in these variables. Especially, mean surface climatology, represented by $A_{0}$, is well estimated by the multiple linear regression models. This is indicated by high $R_{a d j}^{2}$ and low RMSE-values. While a high $R_{a d j}^{2}$ ( $>0.7)$ can be reached with only one variable $\left(n_{\text {snow }}\right)$ for $A_{0, \text { day }}$, multiple variables are needed to reach the same result for $A_{0, \text { night }}$ and $A_{0, \text { diff }}$. When the four variables (elevation, $n_{\text {snow }}$, iNDVI and CTI) are used, predictions for mean day, night and diurnal difference temperatures have a RMSE of $1.88,1.32$ and $2.44^{\circ} \mathrm{C}$, respectively. Annual climatologies $\left(A_{8}\right)$ however, are slightly less well predicted by the linear regression models which might be attributed to the complex shape of the original time series as described in 5.1. Nevertheless, $R_{a d j}^{2}$-values of 0.51 and 0.66 , and a RMSE of 2.39 and $0.99^{\circ} \mathrm{C}$, for $A_{0, \text { day }}$ and $A_{0, n i g h t}$, respectively, show that the model with the four variables is still rather accurate. In contrast, little explanation of the observed variance in $A_{8, d i f f}$ could be explained by the set of physiographical variables used in this study. Partly, this can be attributed to the lower contribution 
of the annual signal to the total amplitude variance, which shows the greater importance of higher-order components. Consequently, $L S T_{\text {diff }}$ shows a less pronounced annual signal and more noise compared to $L S T_{\text {day }}$ and $L S T_{\text {night }}$ as for instance illustrated in Fig.3b. This higher noise level originates from subtracting the two time series $L S T_{d a y}$ and $L S T_{\text {night }}$ and their corresponding white noise, which implies a new time series characterized by white noise with a greater variance (Marsaglia, 1965).

\subsection{1. $A_{0}$}

Observed regional differences in the average component $\left(A_{0}\right)$ illustrate the combined effect of general, topography-related temperature patterns as well as the effect of surface cover on the surface thermal regime.

Topography controls surface temperatures by changing the air temperature due to the environmental lapse rate (Oke, 1987). Consequently, as surface temperatures connect to air temperatures, LST tends to decrease with increasing elevation. In the study area, this effect counts especially at night (Table 1) and as such corresponds to the findings of Fu and Rich (2002) and Pouteau et al. (2011). During daytime, this effect was less present due to the greater importance of surface cover effects. These effects at daytime are illustrated by the significant amelioration produced in the linear regression models when introducing the surface cover variables, $n_{\text {snow }}$ and iNDVI (Table 1).

As such, snow cover duration shows a strong negative linear correlation with $A_{0, \text { day }}$. This relationship is in accordance with the work of Bounoua et al. (2000) and Kaufmann et al. (2003), who reported increasing temperatures on a continental scale coinciding with a reduction in snow cover extent. This increase is caused by the accompanied reduction in surface albedo, which enables a longer exposure of the soil to direct solar radiation. This relationship was the strongest observed in the Kosh Agach region and implies that a shift in snow season length would have a severe impact in the region. For instance, if the snow cover duration decreases with 20 days, which could be attributed to a more pronounced warming in spring, averaged daily surface temperatures would increase with 1.5 degrees. Conversely, temperatures will decrease if the snow season extends. The latter might be expected if winter precipitation increases and spring temperatures remain at the same level. At night however, the absence of direct solar radiation ceases the linearity between $n_{\text {snow }}$ and $A_{0, \text { night }}$.

Vegetation cover has a strong dampening effect on mean LST. Firstly, a 
strong positive connection exists in the study region between the mean night temperature $\left(A_{0, \text { night }}\right)$ on the one hand, and iNDVI on the other $\left(R_{a d j}^{2}=0.47\right)$. This connection illustrates that surface temperatures at night increase as vegetation gets denser. These findings match the results from Van Leeuwen et al. (2011) who reported that non-forested areas in the Brazilian state of Mato Grosso experienced more cooling at night than forests. However, they recorded minimal differences if moisture supply was high. This difference in cooling originates from the nocturnal drainage of air from upper canopy layers towards soil level. As such, the canopies of forest covers show relatively warmer nocturnal temperatures (Goulden et al., 2006). However, this process of small scale temperature inversions in forest covers cannot take place in short-stature vegetation. Moreover, as in short-stature vegetation, LST is a combination of both soil and canopy temperatures (Van Leeuwen et al., 2011), a pocket of cold air, caused by the nocturnal radiative cooling of the land surface, remains in contact with the canopy of sparse and short-stature vegetation. Consequently, nighttime LST-values of these vegetation types will be lower. Secondly, for mean daytime temperatures $\left(A_{0, \text { day }}\right)$, the effect of vegetation is opposite with lower daytime LST for dense vegetation covers than for sparse types (Fig. 5a). A dense canopy efficiently blocks incident shortwave radiation which prevents the surface from a significant temperature increase during daytime. Furthermore, the amount of evapotranspirative cooling increases as vegetation gets more developed due to their access to greater water resources (Van Leeuwen et al., 2011). This effect is minor at night but can be more pronounced if wind speed is high (Oke, 1987). However, this drop in daily LST with an increasing vegetation cover, which has been reported as a linear relationship during the dry season (Nemani et al., 1993), was not observed in the relationship between $A_{0, \text { day }}$ and iNDVI (Table 1 ). The main reason is that $A_{0, d a y}$ aggregates seasonal variation and as such also encompasses the winter season where vegetation effects are less important on the daytime temperature signal. Nevertheless, Fig. 7a clearly shows the strong buffering effect of vegetation cover on the relationship between elevation and $A_{0, \text { day }}$ which is reflected by their high interaction effect (Table 1).

Temperature inversions oppose the general tendency of decreasing temperatures with increasing elevation, which results in a strong bias in linear regression models if this parameter is neglected (Lundquist et al., 2008; Pouteau et al., 2011). Continental mountain systems in general, and the Altay Mountains in particular, are highly sensitive to such inversions. Espe- 
cially in the basins of Chuya and Kuray and on the Ukok plateau, cold air ponds itself up at the valley floor and is reinforced by the katabatic flow from the surrounding mountains. These inversions occur both seasonal (during winter) and diurnal (at night) which results in relatively low $A_{0, n i g h t}$-values and a high annual temperature range. Hence, the introduction of the CTI to linear regression models as a proxy for the sensitivity to these temperature inversions, significantly improves estimations of nocturnal and diurnal temperatures. It however should be noted that CTI is built as a hydrological index, and as such not completely intended to map inversions. Nevertheless, CTI explains significant parts of the variance and as such corresponds to Pouteau et al. (2011), who reported close connection between CTI-values and frost risk assessment.

Finally, topography also determines LST due to regional variation in solar radiation loading. This implies that steep and north oriented slopes get less solar radiation and exhibit lower temperatures (Scherrer and Körner, 2010). However, in contrast to previous studies (Chuanyan et al., 2005; Fu and Rich, 2002), no clear relationship was observed between potSRAD and any of the Fourier components. This corroborates the findings of Daly et al. (2008) and Pouteau et al. (2011) who found that that the effect of slope and insolation play an important role at local scale climatology, but diminishes as the region of interest increases. Therefore, it is expected that solar radiation would play a more significant role if for instance an east-west oriented basin or valley system is taken as study area.

The mean diurnal temperature range $\left(A_{0, d i f f}\right)$ compromises the above mentioned effects of snow and vegetation cover on day and nighttime LST and as such both variables and CTI explain the major part of the variance in $A_{0, \text { diff }}$. In general, diurnal differences decrease with increasing snow cover duration which can be explained by the aforementioned surface temperature lowering during daytime. Furthermore, if a pixel is characterized by a snowfree period, surface temperatures are more resistant to diurnal oscillations as vegetation increases. This resistance is caused by the relative surface warming at night and shading and evapotranspirative cooling during daytime. Moreover, as in this semi-arid environments, higher vegetation types, typical reflect higher soil moistures and a subsequently higher soil heat capacity, day-night surface temperature differences are further reduced (Van Leeuwen et al., 2011). This relation between vegetation-type and soil moisture implies, together with the low precipitation amounts and high evaporation rates in the study area, the importance of snow cover in the water supply. As such, a 
clear relationship between vegetation zonation and snow cover as reported by Kozlowska and Rackowska (2006), can be retrieved, with high iNDVI-values restricted between 75 and 250 snow days. Below 75, soil moisture supply is insufficient to enable a well-developed vegetation cover. Furthermore, the absence of a stable snow cover, also denotes that these pixels experience more low-temperature events, which reduces above ground growth as diagnosed by Wipf et al. (2009) on a alpine tundra site. Consequently, species characterized by winter frost hardiness (steppe taxa) will dominate these areas. Above 250 , the growing season is too short to enable extensive grow.

\subsection{2. $A_{8}$}

Annual amplitudes calculated by the FFT are more difficult to understand as they aggregate the above mentioned effects. In general, the same image is found during daytime and nighttime which shows that to some extent the same processes explain the observed variance in $A_{8}$. Nevertheless, relationships between the explanatory variables and the nocturnal annual amplitude are stronger and as such demonstrate the influence of solar radiation on the annual signal.

CTI is the physiographic variable which explains most of the variance in $A_{8}$ (day and night). This significance of CTI is related to the aforementioned temperature inversions which are vast winter phenomena which creates persistent relatively low negative temperatures in the valley systems of the Altay Mountains. On the other hand, summer temperatures are much warmer in these systems due to their lower altitude.

Although vegetation shows a strong buffering on the annual LST signal as stipulated by Bounoua et al. (2000) and confirmed by Kaufmann et al. (2003) and Jeong et al. (2009), at first sight, no such trend could be reported in the study area. The primary reason for this is the presence of low iNDVI-values both in the lower arid steppe-areas as at high elevated pixels. While the

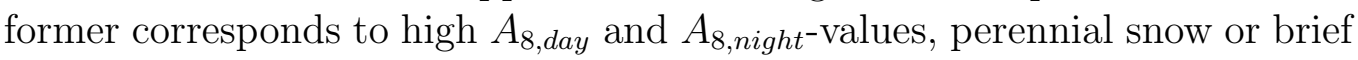
snow-free periods result in low annual amplitudes at the latter. Notwithstanding this, similar to the variation observed in $A_{0, \text { day }}$, strong interaction is observed between iNDVI and elevation. As such, vegetation cover shows its buffering capacity at lower elevations where it dampens the general trend of increasing annual amplitude with decreasing elevation (Fig. 7d and 8d). However, it has to be noted this general trend might be strongly related to case-specific regional variability in snow and land cover.

Finally, little predictive power was achieved by the linear regression model 
for $A_{8, \text { diff }}$ (see section 5.2). Despite this, an interesting observation was made concerning the difference in timing of the maximum diurnal range. In general, for the gross of the study area, this maximum occurred in early summer, shortly after the snow cover disappeared. Hence, this timing coincides with the removal of the buffering snow layer and precedes the grow of a wellbuilt vegetation cover. As a result, the soil is subject to both strong heating during daytime and fast cooling at night. Contrary, perennial snowfields remain their buffer layer throughout the year although a significant change in physical properties is observed in summer: at first, due to a strong radiative forcing, snow is melting, which happens even on the highest peaks of the Altay Mountains. This is reflected in surface temperatures which are both during daytime as at night close to $0^{\circ} \mathrm{C}$, as illustrated e.g. in Fig. 5a and b. Because of this melt, snow grain size increases which subsequently creates a drop in albedo and thus enhances solar radiation absorption (Hall et al., 2008). Secondly, melting snow requires latent heat, which transforms the upper part of the snowpack isothermal, which in turn lowers the sensible heat flux. As this second effect dominates the increased absorption of shortwave radiation, this melting period corresponds to the annual minimum in the diurnal temperature difference.

\subsection{Spatial variability and implications for the Russian Altay Mountains}

The steppe areas, characteristic for the topographical basins in the Kosh Agach Region and great parts of north-west Mongolia, are extreme ecosystems which exhibit very strong annual oscillations. These ecosystems originate from the lack of available soil moisture, and are therefore typically confined to the valley bottoms. As these topographical settings are subject to strong winds, no stable snowpack is able to built up during winter. Together with the lack of precipitation in the region, this means that insufficient soil moisture is available to enable extensive grow. Consequently, steppe taxa, which can endure soil moisture deficits and extreme temperature events, due to the severe temperature inversions, will dominate these areas. In turn, this steppe vegetation is marked by limited surface shading and therefore prone to strong surface heating during daytime in snow-free periods. In contrast, these environments are also subject to more pronounced nocturnal radiative cooling in summer due to the absence of a protective cover. Despite their uniform appearance, significant regional differences can be detected between different steppe zones. For instance, significantly lower annual day and (to lesser extent) nighttime amplitudes are observed in the Mongolian steppe 
when compared to the Chuya and Kuray steppes (Fig. 4b and d). This difference in $A_{8, \text { day }}$ and $A_{8, n i g h t}$ can be attributed to far more extensive temperature inversions which occur in the Russian basins which result in much lower temperatures during winter, although summer LST values are alike (Fig. 5a and b). Secondly, despite overall high values in $A_{0, d i f f}$, the annual amplitude of the diurnal difference is much lower in the Mongolian Steppes. This effect is ascribed to the absence of snow cover in this Mongolian steppe which contrasts with considerable snow duration in the Russian steppes (Fig. $2 \mathrm{~b})$. As a result, no winter buffer layer is present in the former which prevents the surface from significant diurnal fluctuations (Fig. 5c). Hence, these areas show smaller annual oscillations opposed to e.g. the Chuya Steppe where diurnal temperature differences drop in winter below ten degrees.

Although located 500 meters above the Chuya Steppe, very similar conditions are retrieved on the Ukok Plateau. This high elevated plateau, is surrounded by high mountain ranges and as a consequence also prone to severe temperature inversions. On the other hand, summer temperatures (both day and night) are somewhat lower on this plateau (Fig. 5a and b), which can be explained by the environmental lapse rate. This difference is reflected in lower $A_{0}$ and $A_{8}$-values compared to the Chuya Steppe.

If sufficient soil moisture is available, low shrubs or even coniferous forests are able to develop in the region. This soil moisture can be related to higher precipitation amounts or the proximity of a stream, which is for example the case in the Katun River Valley located in the northwest of the study area (dominated by coniferous forests), and in the Chuya River Plain (a stretch of fertile land covered with dwarf willows and moist grass in the middle of the semi-dessert). Thanks to their access to water and surface shading, these regions are protected to strong heating and cooling, which is reflected in much more moderate surface temperatures. However, as canopy density is much larger for coniferous forests, this effect is more pronounced in the northwest. Moreover, little effect of this protective cover is observed in the winter temperatures at the Chuya river. Finally, at high mountain ranges, perennial snow acts as an efficient buffer against strong, both diurnal and annual, heating and cooling. Consequently, a removal of this snow layer would have a dramatic effect on the surface temperature. 


\section{Conclusion}

In this study the ability of the Fast Fourier Transform to discriminate between high frequency noise and fundamental periodics was used. As such, strong, climate related periodic patterns, could be separated from short-term weather signals. This allowed to assess the influence of five physiographic variables by multiple regression analysis on the spatio-temporal variability, observed in eight years of $L S T_{\text {day }}, L S T_{\text {night }}$ and $L S T_{\text {diff }}$-time series in the Russian Altay Mountains. Most of the temporal variance was constrained to the average $\left(A_{0}\right)$ and annual signal $\left(A_{8}\right)$ which is explained by the continentality of the study area. Snow cover duration showed a strong inverse relationship with the averaged diurnal difference and daytime LST, caused by the high albedo of the snow cover, which reduces the absorption of shortwave radiation. Nocturnal average LST was mainly influenced by the environmental lapse rate and the vegetation cover which prevents strong radiative cooling. The amplitude of the annual daytime $\left(A_{8, \text { day }}\right)$ and nighttime $\left(A_{8, \text { night }}\right)$ signal showed a strong connection with CTI which demonstrates the importance of severe temperature inversions in the region. Furthermore, also the combined effect of vegetation and elevation explained large parts of the variance in $A_{8, \text { day }}$ and $A_{8, n i g h t}$. However, limited connection was retrieved between $A_{8, d i f f}$ and the set of physiographic variables, although a significant difference in temporal behavior was noticed between the majority of the study region and the perennial snowfields. The latter can be attributed to the summer snow melt of the upper layers which reduces the diurnal range. Based on the results from the FFT and multiple regression analysis, it was possible to differentiate the steppe zones, characterized by extreme temperatures, from the more moderate forests, river valleys and perennial snowfields, which are buffered by their surface cover and moisture supply.

\section{Acknowledgements}

This study was funded by the Flemish Agency for the promotion of Innovation by Science and Technology (IWT). Part of this work was carried out at the Jet Propulsion Laboratory, California Institute of Technology, under a contract with the National Aeronautics and Space Administration. The JPL author's copyright for this publication is held by the California Institute of Technology. 


\section{References}

Azzali, S., Menenti, M., 2000. Mapping vegetation-soil-climate complexes in Southern Africa using temporal Fourier analysis of NOAA-AVHRR NDVI data. International Journal of Remote Sensing 21, 973-996.

Baker, V., Benito, G., Rudoy, A.N., 1993. Paleohydrology of late Pleistocene superflooding, Altay Mountains, Siberia. Science 259, 348-350.

Bastiaanssen, W.G.M., Menenti, M., Feddes, R.A., Holtslag, A.A.M., 1998. A remote sensing surface energy balance algorithm for land (SEBAL). 1. Formulation. Journal of Hydrology 212-213, 198-212.

Bounoua, L., Collatz, G.J., Los, S.O., Sellers, P.J., Dazlich, D.A., Tucker, C.J., Randall, D.A., 2000. Sensitivity of climate to changes in NDVI. Journal of Climate 13, 2277-2292.

Bracewell, R., 2000. The Fourier transform and its applications (third edition). McGraw Hill, Boston.

Chen, J., Jönsson, P., Tamura, M., Gu, Z., Matsushita, B., Eklundh, L., 2004. A simple method for reconstructing a high-quality NDVI time-series data set based on the Savitzky-Golay filter. Remote Sensing of Environment 91, 332-344.

Chen, X.L., Zhao, H.M., Li, P.X., Yin, Z.Y., 2006. Remote sensing imagebased analysis of the relationship between urban heat island and land use/cover changes. Remote Sensing of Environment 104, 133-146.

Chuanyan, Z., Zhongren, N., Guodong, C., 2005. Methods for modelling of temporal and spatial distribution of air temperature at landscape scale in the southern Qilian mountains, China. Ecological Modelling 189, 209-220.

Clements, C.B., Whiteman, C.D., Horel, J.D., 2003. Cold-air-pool structure and evolution in a mountain basin: Peter Sinks, Utah. Journal of Applied Meteorology 42, 752 .

Coll, C., Caselles, V., Galve, J.M., Valor, E., Niclòs, R., Sánchez, J.M., Rivas, R., 2005. Ground measurements for the validation of land surface temperatures derived from AATSR and MODIS data. Remote Sensing of Environment 97, 288-300. 
Coppin, P., Jonckheere, I., Nackaerts, K., Muys, B., Lambin, E., 2004. Digital change detection methods in ecosystem monitoring: a review. International Journal of Remote Sensing 25, 1565-1596.

Daly, C., Halbleib, M., Smith, J.I., Gibson, W.P., Doggett, M.K., Taylor, G.H., Curtis, J., Pasteris, P.P., 2008. Physiographically sensitive mapping of climatological temperature and precipitation across the conterminous United States. International Journal of Climatology 28, 2031-2064.

Eastman, J., Fulk, M., 1993. Long sequence time series evaluation using standardized principal components. Photogrammetic Engineering and Remote Sensing 59, 991-996.

Evans, J.P., Geerken, R., 2006. Classifying rangeland vegetation type and coverage using a Fourier component based similarity measure. Remote Sensing of Environment 105, 1-8.

Fu, P., Rich, P.M., 2002. A geometric solar radiation model with applications in agriculture and forestry. Computers and Electronics in Agriculture 37, $25-35$.

Fukui, K., Fujii, Y., Mikhailov, N., Ostanin, O., Iwahana, G., 2007. The lower limit of mountain permafrost in the Russian Altai Mountains. Permafrost and Periglacial Processes 18, 129-136.

Gheyle, W., 2009. Highlands and steppes. An analysis of the changing archaeological landscape of the Altay Mountains from the Eneolithic to the Ethnographic period. Ph.D. thesis. Ghent Univeristy.

Goossens, R., Van De Kerchove, R., Bourgeois, J., Gheyle, W., Ebel, A., 2009. Permafrost research in the valley of Dzhazator, and on the Plateaus of Tarkhata and Ukok (Russian Altay Mountains, Kosh Agatch District). Technical Report. Ghent University, Department of Geograpy.

Goulden, M.L., Miller, S.D., da Rocha, H.R., 2006. Nocturnal cold air drainage and pooling in a tropical forest. Journal of Geophysical Research 111, D08S04.

Gruber, S., Peckham, S., Hengl, T., Reuter, H., 2009. Chapter 7 Landsurface parameters and objects in hydrology, in: Hengl, T., Reuter, H. (Eds.), Developments in Soil Science. Elsevier. volume 33, pp. 171-194. 
Hachem, S., Allard, M., Duguay, C., 2009. Using the MODIS Land Surface Temperature product for mapping permafrost: An application to northern Québec and Labrador, Canada. Permafrost and Periglacial Processes 20, 407-416.

Hall, D., Riggs, G., 2007. Accuracy assessment of the MODIS snow-cover products. Hydrological Processes 21, 1534-1547.

Hall, D.K., Box, J.E., Casey, K.A., Hook, S.J., Shuman, C.A., Steffen, K., 2008. Comparison of satellite-derived and in-situ observations of ice and snow surface temperatures over Greenland. Remote Sensing of Environment 112, 3739-3749.

Hjort, J., Etzelmüller, B., Tolgensbakk, J., 2010. Effects of scale and data source in periglacial distribution modelling in a high Arctic environment, western Svalbard. Permafrost and Periglacial Processes 21, 345-354.

Holben, B.N., 1986. Characteristics of maximum-value composite images from temporal AVHRR data. International Journal of Remote Sensing 7, $1417-1434$.

Holden, Z.A., Crimmins, M.A., Cushman, S.A., Littell, J.S., 2010. Empirical modeling of spatial and temporal variation in warm season nocturnal air temperatures in two north Idaho mountain ranges, USA. Agricultural and Forest Meteorology 151, 261-269.

Jakubauskas, M., Kastens, J., Legates, D., 2001. Harmonic analysis of timeseries AVHRR NDVI data. Photogrammetic Engineering and Remote Sensing 67, 461-470.

Jarvis, A., Reuter, H., Nelson, A., Guevara, E., 2008. Hole-filled SRTM for the globe version 4 .

Jeong, S.J., Ho, C.H., Jeong, J.H., 2009. Increase in vegetation greenness and decrease in springtime warming over East Asia. Geophysical Research Letters 36, L02710.

Jönsson, P., Eklundh, L., 2002. Seasonality extraction by function fitting to time-series of satellite sensor data. IEEE Transactions on Geoscience and Remote Sensing 40, 1824-1832. 
Jönsson, P., Eklundh, L., 2004. TIMESAT - a program for analysing timeseries of satellite sensor data. Computers and Geosciences 30, 833-845.

Julien, Y., Sobrino, J.A., 2010. Comparison of cloud-reconstruction methods for time series of composite NDVI data. Remote Sensing of Environment $114,618-625$.

Julien, Y., Sobrino, J.A., Verhoef, W., 2006. Changes in land surface temperatures and NDVI values over Europe between 1982 and 1999. Remote Sensing of Environment 103, 43-55.

Justice, C.O., Townshend, J.R.G., Vermote, E.F., Masuoka, E., Wolfe, R.E., Saleous, N., Roy, D.P., Morisette, J.T., 2002. An overview of MODIS land data processing and product status. Remote Sensing of Environment 83, $3-15$.

Karnieli, A., Agam, N., Pinker, R.T., Anderson, M., Imhoff, M.L., Gutman, G.G., Panov, N., Goldberg, A., 2010. Use of NDVI and land surface temperature for drought assessment: Merits and limitations. Journal of Climate 23, 618-633.

Kaufmann, R.K., Zhou, L., Myneni, R.B., Tucker, C.J., Slayback, D., Shabanov, N.V., Pinzon, J., 2003. The effect of vegetation on surface temperature: A statistical analysis of NDVI and climate data. Geophysical Research Letters 30, 2147.

Klinge, M., Böhner, J., Lehmkuhl, F., 2003. Climate patterns, snow-and timberline in the Altai Mountains, Central Asia. Erdkunde 57, 296-308.

König, P., Rilke, S., 2004. Vegetation pattern within a thermokarst landscape in the central Altay Mountains (west Siberia). Journal of Botanical Taxonomy and Geobotany 115, 574-584.

Kozlowska, A., Rackowska, Z., 2006. Effect of snow patches on the vegetation in the high-mountain nival gullies (Tatra Mts. Poland). Polish Journal of Ecology 54, 69-90.

Kumar, L., Skidmore, A., Knowles, E., 1997. Modelling topographic variation in solar radiation in a GIS environment. International Journal of Geographical Information Science 11, 475-497. 
Langer, M., Westermann, S., Boike, J., 2010. Spatial and temporal variations of summer surface temperatures of wet polygonal tundra in Siberia - implications for MODIS LST based permafrost monitoring. Remote Sensing of Environment 114, 2059-2069.

Lhermitte, S., Verbesselt, J., Jonckheere, I., Nackaerts, K., van Aardt, J.A., Verstraeten, W.W., Coppin, P., 2008. Hierarchical image segmentation based on similarity of NDVI time series. Remote Sensing of Environment $112,506-521$.

Lhermitte, S., Verbesselt, J., Verstraeten, W.W., Coppin, P., 2011. A comparison of time series similarity measures for classification and change detection of ecosystem dynamics. Remote Sensing of Environment DOI: 10.1016/j.rse.2011.06.020.

Liu, Y., Hiyama, T., Yamaguchi, Y., 2006. Scaling of land surface temperature using satellite data: A case examination on ASTER and MODIS products over a heterogeneous terrain area. Remote Sensing of Environment 105, 115-128.

Loyarte, M.M.G., Menenti, M., Diblasi, A.M., 2008. Modelling bioclimate by means of Fourier analysis of NOAA-AVHRR NDVI time series in Western Argentina. International Journal of Climatology 28, 1175-1188.

Lundquist, J.D., Pepin, N., Rochford, C., 2008. Automated algorithm for mapping regions of cold-air pooling in complex terrain. Journal of Geophysical Research 113, D22107.

Manzo-Delgado, L., Sanchez-Colon, S., Alvarez, R., 2009. Assessment of seasonal forest fire risk using NOAA-AVHRR: a case study in central Mexico. International Journal of Remote Sensing 30, 4991-5013.

Marchenko, S., 2007. On preliminary permafrost investigation in the Ulandryk Valley, Altai Mountains, within the framework of the UNESCO project, The Frozen Tombs of the Altai Mountains, in the summer of 2006, in: Bourgeois, J., Gheyle, W. (Eds.), UNESCO report: The Frozen Tombs of the Altai Mountains, Phase 1: 2005-2006, pp. 63-66.

Marsaglia, G., 1965. Ratios of normal variables and ratios of sums of uniform variables. Journal of the American Statistical Association 60, 193-204. 
McCarthy, J., Canzani, O., Leary, N., Dokken, D., White, K., 2001. Climate Change 2001: Impacts, Adaptation, and Vulnerability Report of IPCC Working Group II. Cambridge University Press.

Menenti, M., Azzali, S., Verhoef, W., van Swol, R., 1993. Mapping agroecological zones and time lag in vegetation growth by means of fourier analysis of time series of NDVI images. Advances in Space Research 13, 233-237.

Moody, A., Johnson, D.M., 2001. Land-surface phenologies from AVHRR using the Discrete Fourier Transform. Remote Sensing of Environment 75, 305-323.

NCDC, 2008. Workshop report, in: International Workshop on the Retrieval and Use of Land Surface Temperature: Bridging the Gaps, Asheville, NC.

Nemani, R., Pierce, L., Running, S., Goward, S., 1993. Developing satellitederived estimates of surface moisture status. Journal of Applied Meteorology $32,548-557$.

Oke, T., 1987. Boundary Layer Climates (Second Edition). Methuen, London and New York.

Olsson, L., Eklundh, L., 1994. Fourier series for analysis of temporal sequences of satellite sensor imagery. International Journal of Remote Sensing 15, 3735-3741.

Pelánková, B., Chytrý, M., 2009. Surface pollen-vegetation relationships in the forest-steppe, taiga and tundra landscapes of the Russian Altai Mountains. Review of Palaeobotany and Palynology 157, 253-265.

Pouteau, R., Rambal, S., Ratte, J.P., Gogé, F., Joffre, R., Winkel, T., 2011. Downscaling MODIS-derived maps using GIS and boosted regression trees: The case of frost occurrence over the arid Andean highlands of Bolivia. Remote Sensing of Environment 115, 117-129.

Quinn, P., Beven, K., Chevallier, P., Planchon, O., 1991. The prediction of hillslope flow paths for distributed hydrological modelling using digital terrain models. Hydrological Processes 5, 59-79.

Reed, B., Brown, J.F., VanderZee, D., Loveland, T.R., Merchant, J.W., Ohlen, D.O., 1994. Measuring phenological variability from satellite imagery. Journal of Vegetation Science 5, 703-714. 
Reed, B., Budde, M., Spencer, P., Miller, A.E., 2009. Integration of MODISderived metrics to assess interannual variability in snowpack, lake ice, and NDVI in southwest Alaska. Remote Sensing of Environment 113, 14431452 .

Reuter, H.I., Nelson, A., Jarvis, A., 2007. An evaluation of void-filling interpolation methods for SRTM data. International Journal of Geographical Information Science 21, 983-1008.

Roerink, G.J., Menenti, M., Verhoef, W., 2000a. Reconstructing cloudfree NDVI composites using Fourier analysis of time series. International Journal of Remote Sensing 21, 1911-1917.

Roerink, G.J., Su, Z., Menenti, M., 2000b. S-SEBI: A simple remote sensing algorithm to estimate the surface energy balance. Physics and Chemistry of the Earth, Part B: Hydrology, Oceans and Atmosphere 25, 147-157.

Rudoy, A.N., 2002. Glacier-dammed lakes and geological work of glacial superfloods in the Late Pleistocene, southern Siberia, Altai Mountains. Quaternary International 87, 119-140.

Sandholt, I., Rasmussen, K., Andersen, J., 2002. A simple interpretation of the surface temperature/vegetation index space for assessment of surface moisture status. Remote Sensing of Environment 2002, 213-224.

Scharlemann, J.P.W., Benz, D., Hay, S.I., Purse, B.V., Tatem, A.J., Wint, G.R.W., Rogers, D.J., 2008. Global data for ecology and epidemiology: A novel algorithm for temporal Fourier processing MODIS data. PLoS ONE 3 , e1408.

Scherrer, D., Körner, C., 2010. Infrared thermometry of alpine landscapes challenges climatic warming projections. Global Change Biology 16, 26022613.

Shaghedanova, M., Mikhalov, N., Larin, S., Bredikhin, A., 2002. Mountains of southern Siberia, in: Shaghedanova, M. (Ed.), The Physical Geography of Northern Eurasia: Russia and Neighbouring States. Oxford University Press, Oxford, pp. 314-349.

Singleton, R., 1969. An algorithm for computing the mixed radix fast Fourier transform. IEEE Transactions on Audio and Electroacoustics 17, 93-103. 
Sobrino, J.A., Kharraz, J.E., Li, Z.L., 2003. Surface temperature and water vapour retrieval from MODIS data. International Journal of Remote Sensing 24, 5161-5182.

Sun, D., Pinker, R.T., 2004. Case study of soil moisture effect on land surface temperature retrieval. IEEE Geoscience and Remote Sensing Letters 1, $127-130$.

Van Leeuwen, T., Frank, A., Jin, Y., Smyth, P., Goulden, M.L., van der Werf, G., Randerson, J., 2011. Optimal use of land surface temperature data to detect changes in tropical forest cover. Journal of Geophysical Research - Biogesciences Doi:10.1029/2010JG001488.

Veraverbeke, S., Verstraeten, W., Lhermitte, S., Van De Kerchove, R., Goossens, R., in review. Satellite assessment of post-fire changes in land surface temperature, surface albedo and thermal inertia. International Journal of Wildland Fire .

Verbesselt, J., Hyndman, R., Zeileis, A., Culvenor, D., 2010. Phenological change detection while accounting for abrupt and gradual trends in satellite image time series. Remote Sensing of Environment 114, 2970-2980.

Verstraeten, W.W., Veroustraete, F., van der Sande, C.J., Grootaers, I., Feyen, J., 2006. Soil moisture retrieval using thermal inertia, determined with visible and thermal spaceborne data, validated for European forests. Remote Sensing of Environment 101, 299-314.

Wagenseil, H., Samimi, C., 2006. Assessing spatiotemporal variations in plant phenology using Fourier analysis on NDVI time series: results from a dry savannah environment in Namibia. International Journal of Remote Sensing 27, 3455-3471.

Wan, Z., 2008. New refinements and validation of the MODIS Land-Surface Temperature/Emissivity products. Remote Sensing of Environment 112, 59-74.

Weng, Q., Lu, D., Schubring, J., 2004. Estimation of land surface temperature-vegetation abundance relationship for urban heat island studies. Remote Sensing of Environment 89, 467-483. 
Westermann, S., Langer, M., Boike, J., 2010. Spatial and temporal variations of summer surface temperatures of high-arctic tundra on Svalbard - implications for MODIS LST based permafrost monitoring. Remote Sensing of Environment 115, 908-922.

Wipf, S., Stoeckli, V., Bebi, P., 2009. Winter climate change in alpine tundra: plant responses to changes in snow depth and snowmelt timing. Climatic Change 94, 105-121.

Zhang, T., 2005. Influence of the seasonal snow cover on the ground thermal regime: An overview. Reviews of Geophysics 43, RG4002.

Zhang, X., Friedl, M.A., Schaaf, C.B., Strahler, A.H., Hodges, J.C.F., Gao, F., Reed, B.C., Huete, A., 2003. Monitoring vegetation phenology using MODIS. Remote Sensing of Environment 84, 471-475.

Zhigulskaya, Z., 2009. The ants of the Chuya depression and the Yustyd river basin in Southeastern Altai. Contemporary Problems of Ecology 2, $210-215$. 
1071 8. Figures \& captions 

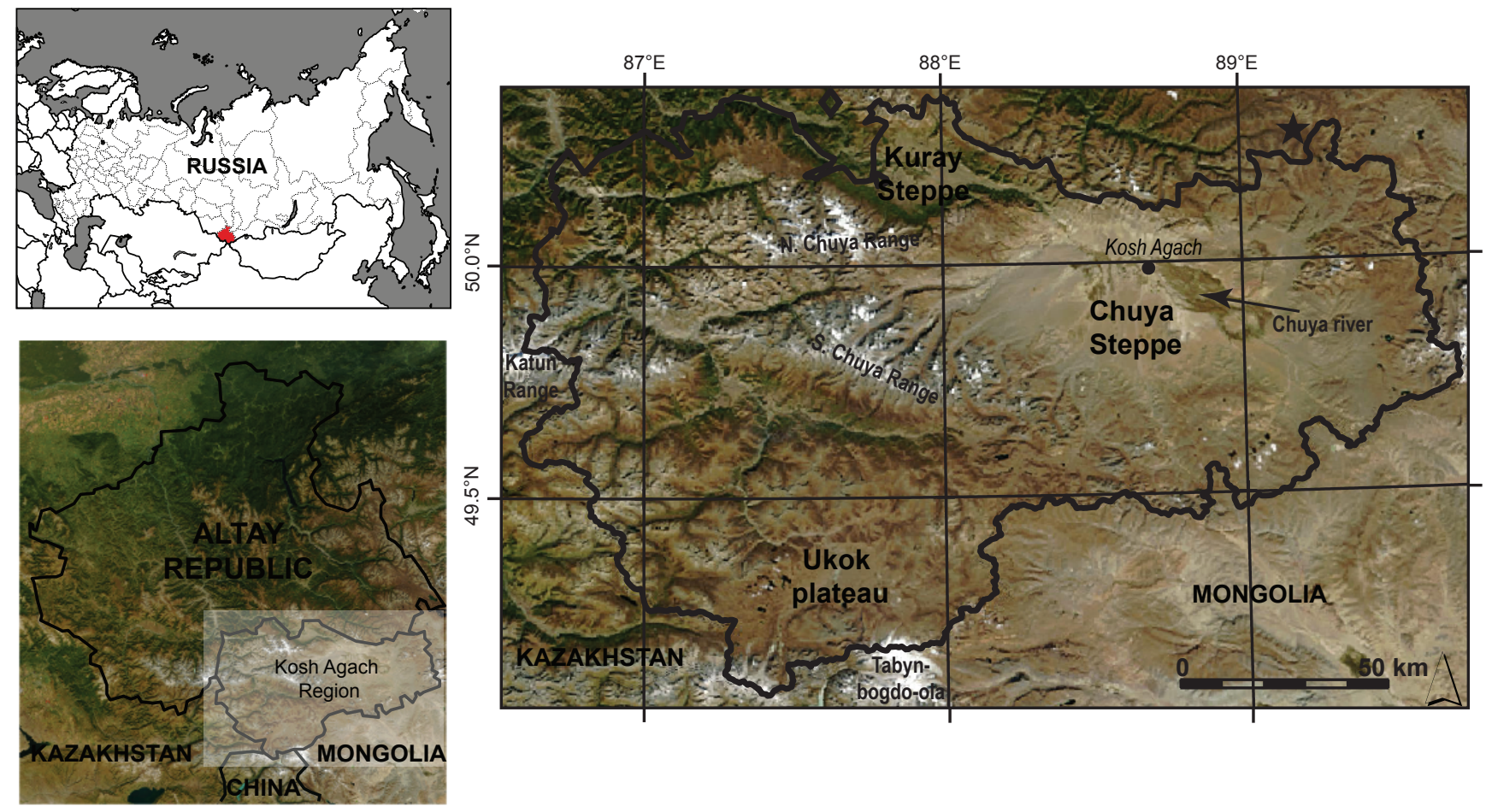

Figure 1: Location of the study area, a Landsat TM (RGB-321) image is used as background. To increase the knowledge about the regional variability, the border areas around the Kosh-Agach region were included. Consequently, the region of interest was extended to the rectangle showed, covering parts of Russia, Mongolia, Kazakhstan and China 

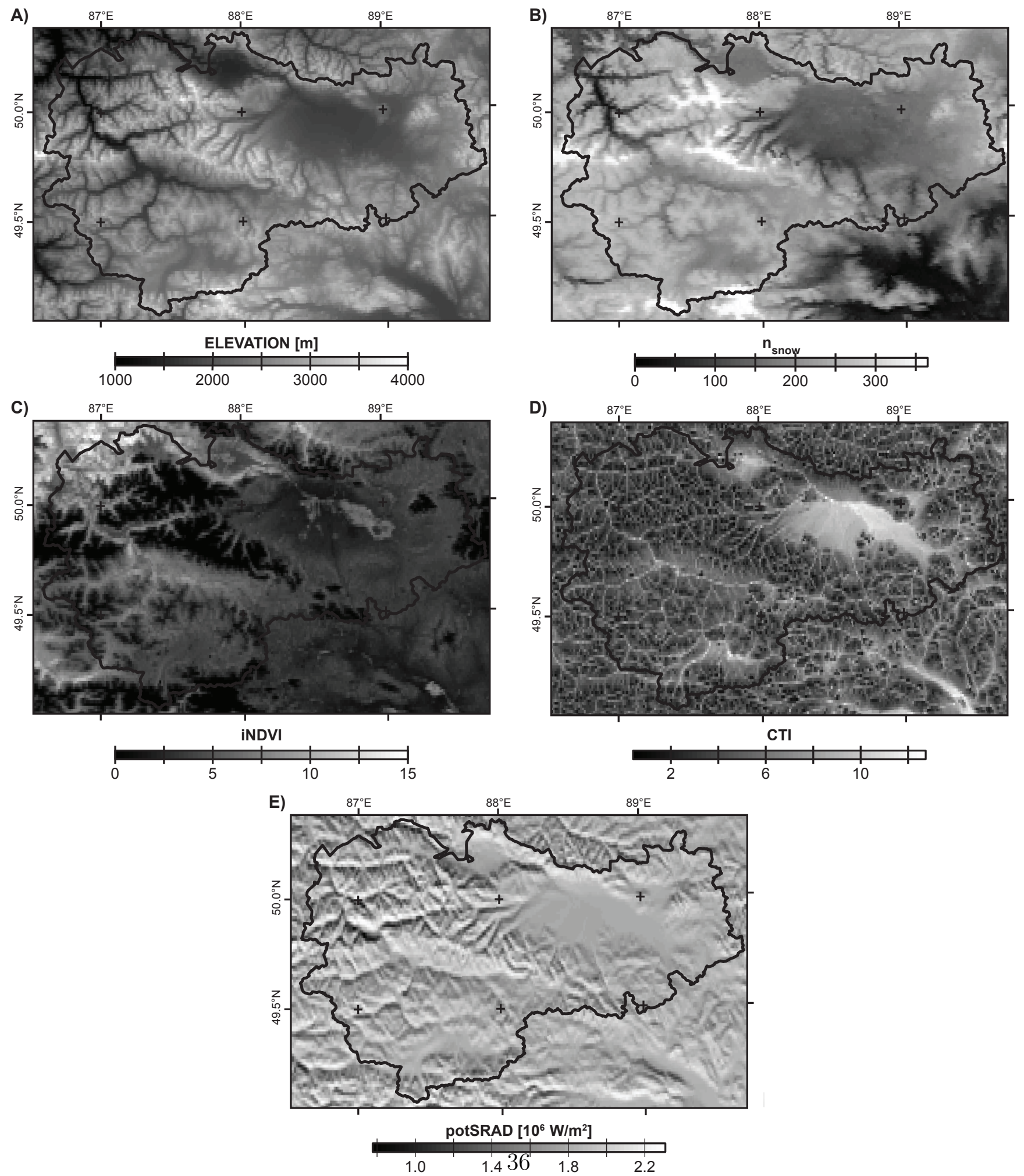

Figure 2: Elevation (a), $n_{\text {snow }}(\mathrm{b})$, iNDVI (c), CTI (d) and potSRAD (e) for the study area. 

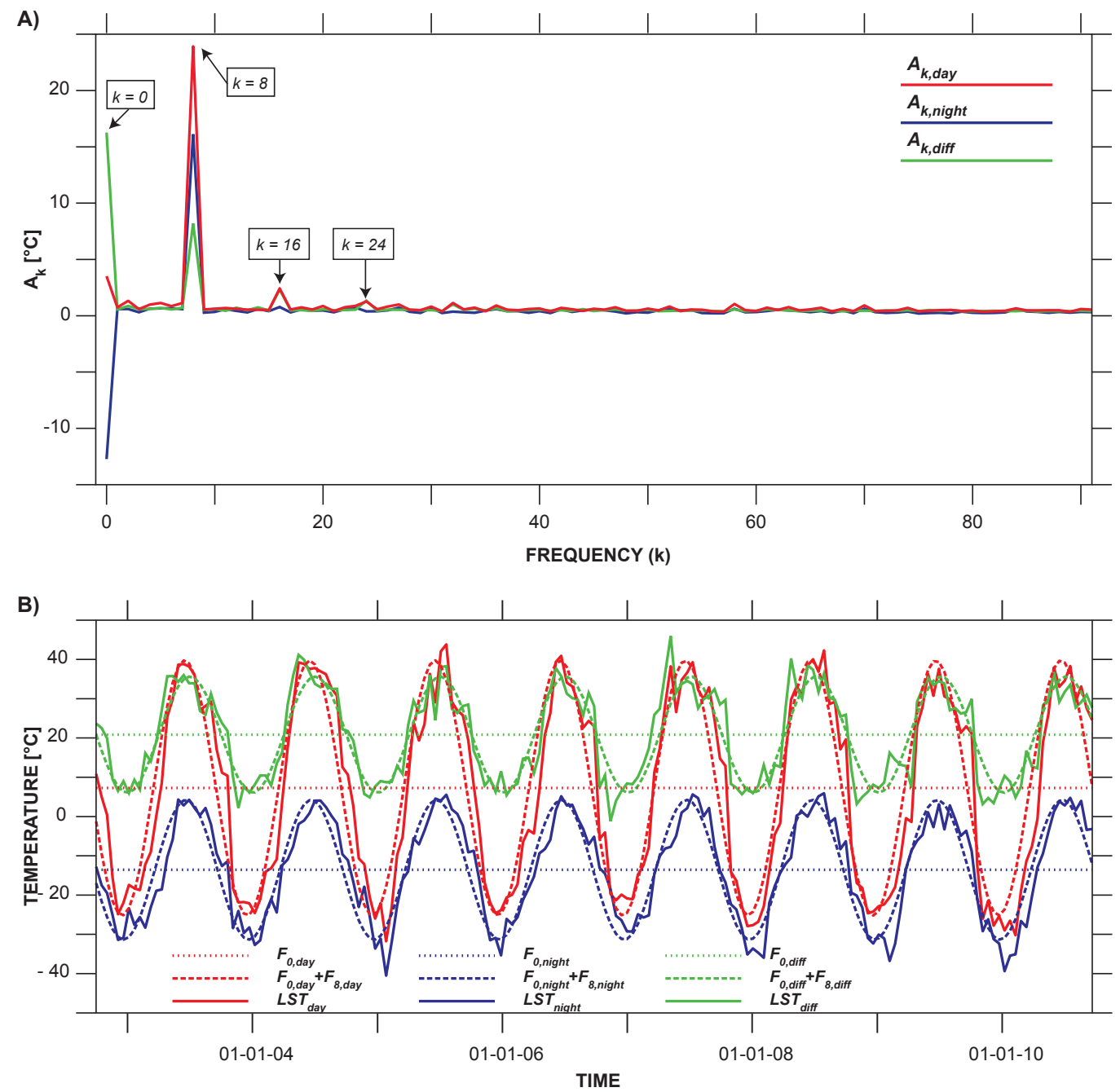

Figure 3: a) Regional averaged, single sided amplitude spectrum of the FFT analysis for the three LST variables. b) 16-day LST time composites for a random pixel and their respective Fourier decomposition. The sum of the mean and the annual harmonics results in a good approximation of the actual LST curve. 

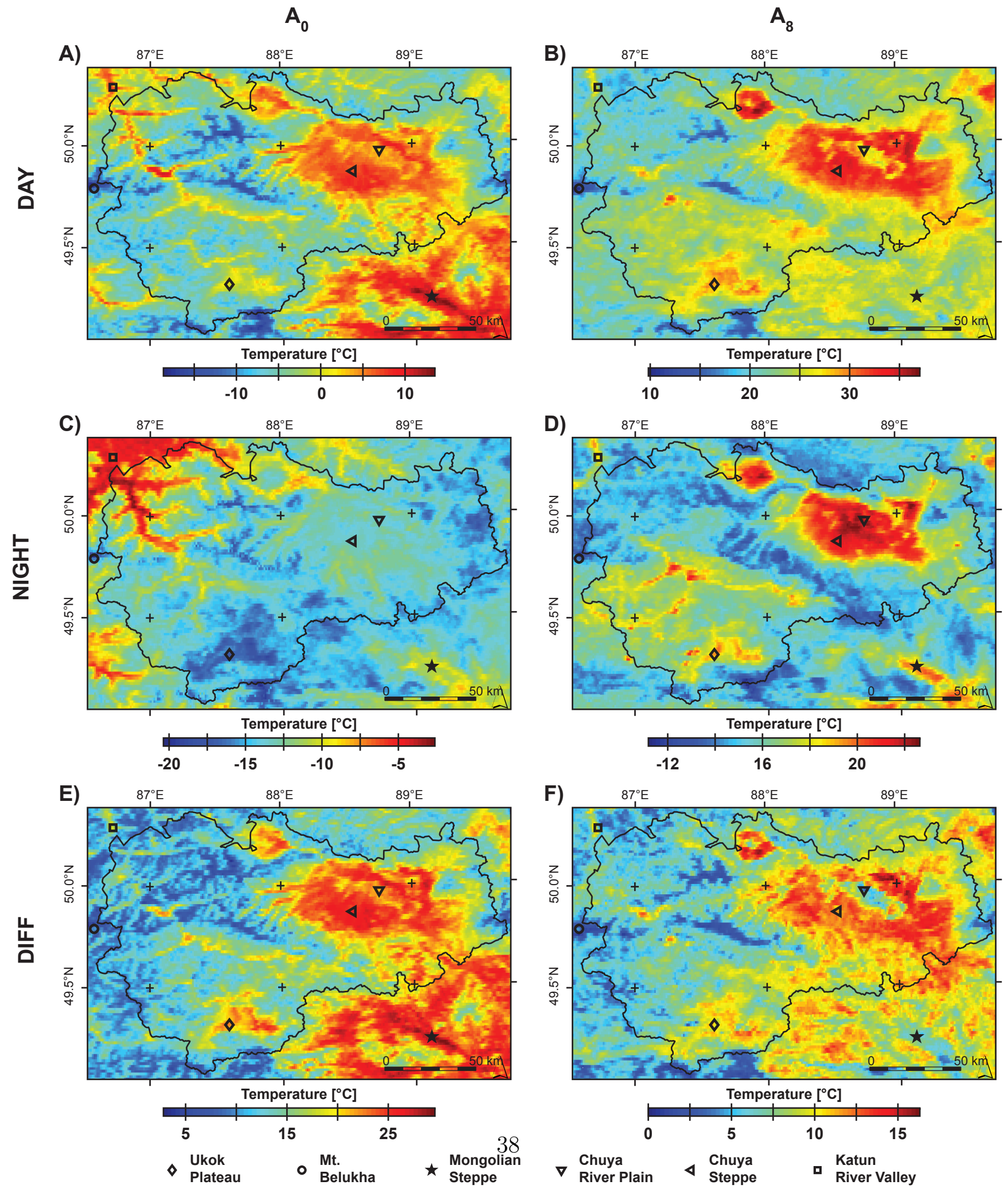

Figure 4: Spatial variability in amplitudes of the $0^{\text {th }}(\mathrm{a}, \mathrm{c}, \mathrm{e})$ and $8^{\text {th }}(\mathrm{b}, \mathrm{d}, \mathrm{f})$ FFTcomponent for $L S T_{\text {day }}(\mathrm{a}, \mathrm{b}), L S T_{\text {night }}$ (c, d) and $L S T_{\text {diff }}(\mathrm{e}, \mathrm{f})$. The locations of the six pixels, represented in Fig. 5 are marked by their corresponding symbol. 


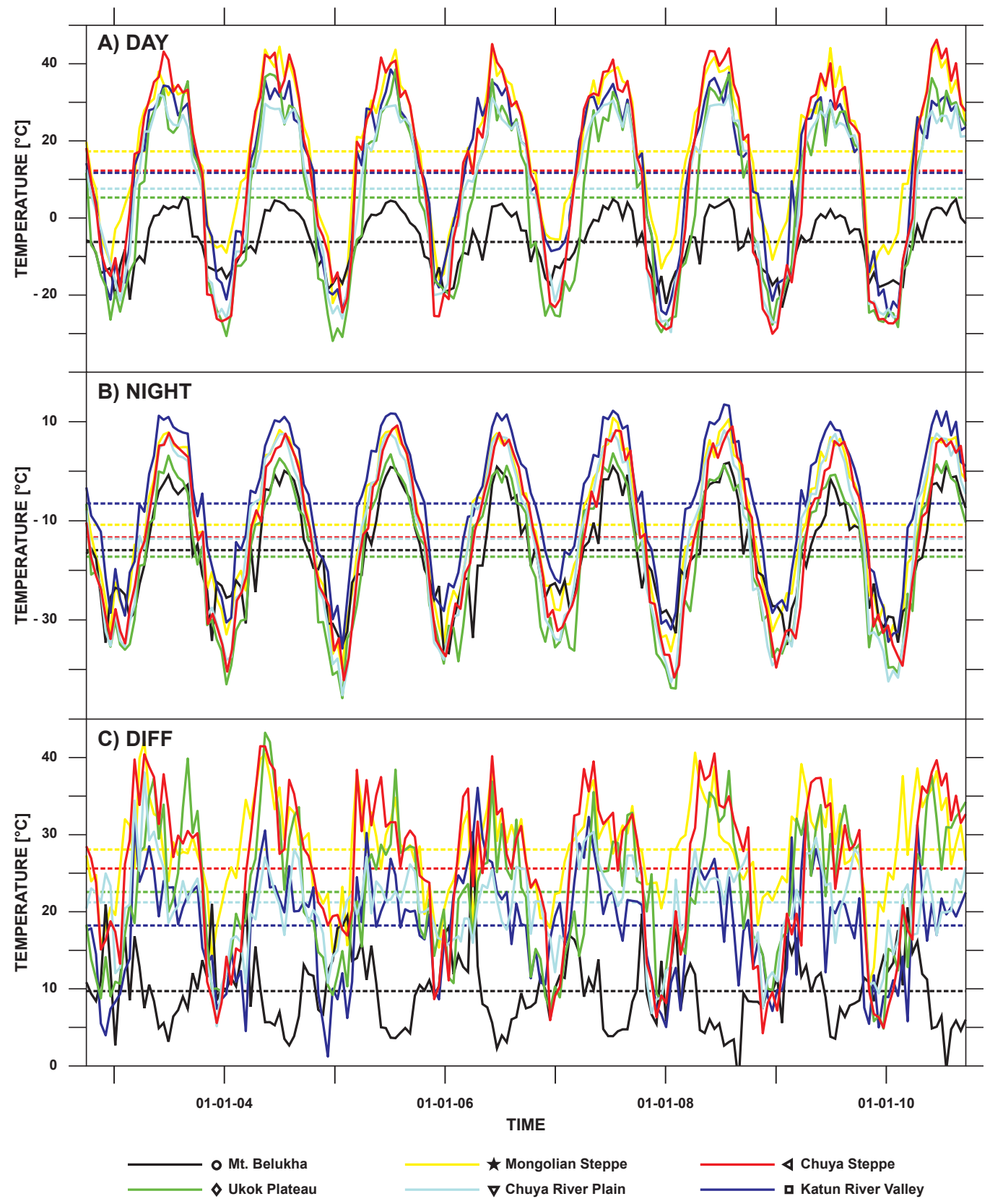

Figure 5: 16-day $L S T_{\text {day }}$ (a), $L S T_{\text {night }}$ (b) and $L S T_{\text {diff }}$ (c) composites for six characteristic pixels. The location of these pixels is indicated by their corresponding symbol in Fig. 4. 


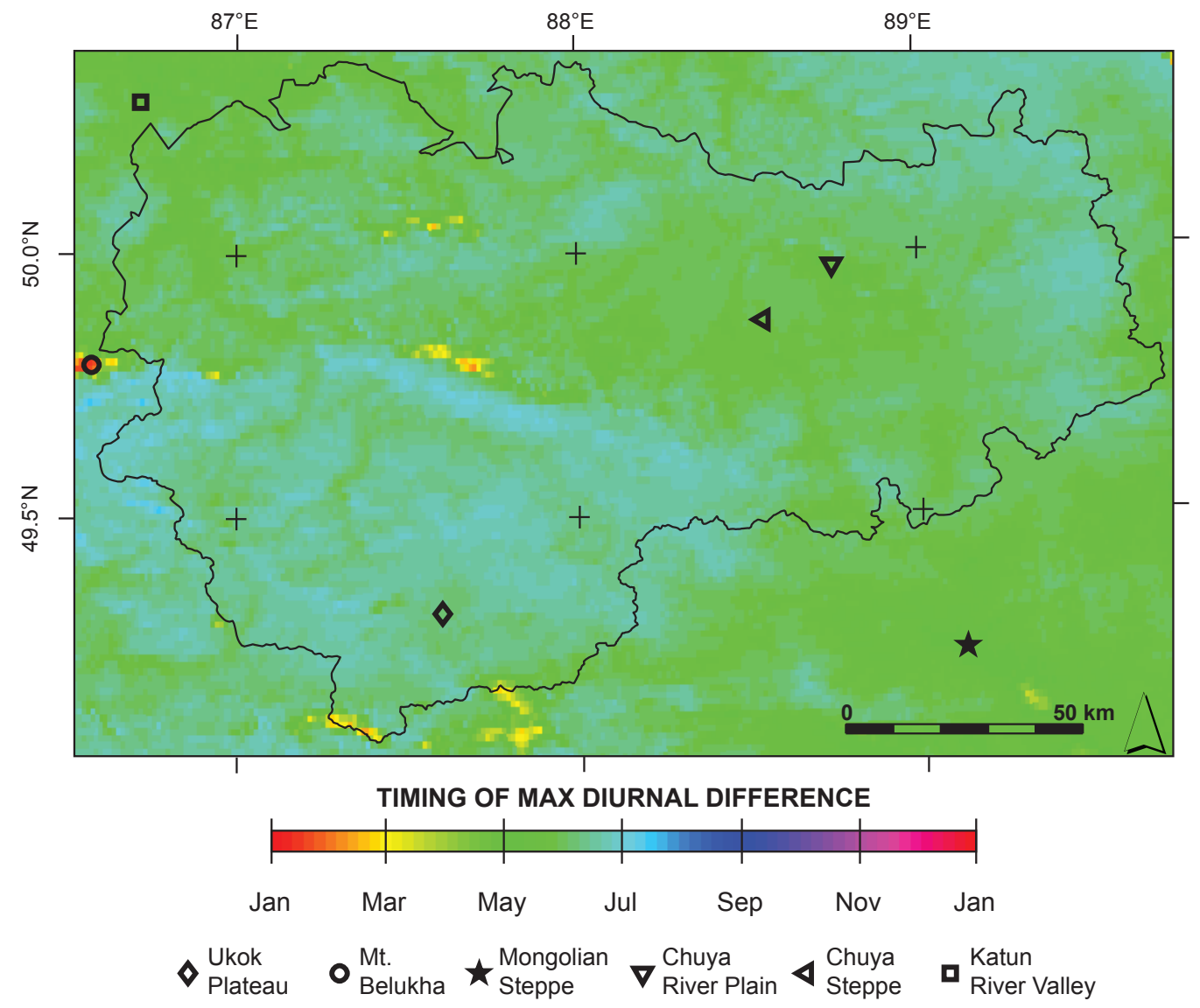

Figure 6: Timing of the maximum in the maximum diurnal difference $\left(A_{8, \text { diff }}\right)$ in the study area. The locations of the six pixels, represented in Fig. 5 are marked by their corresponding symbol. 


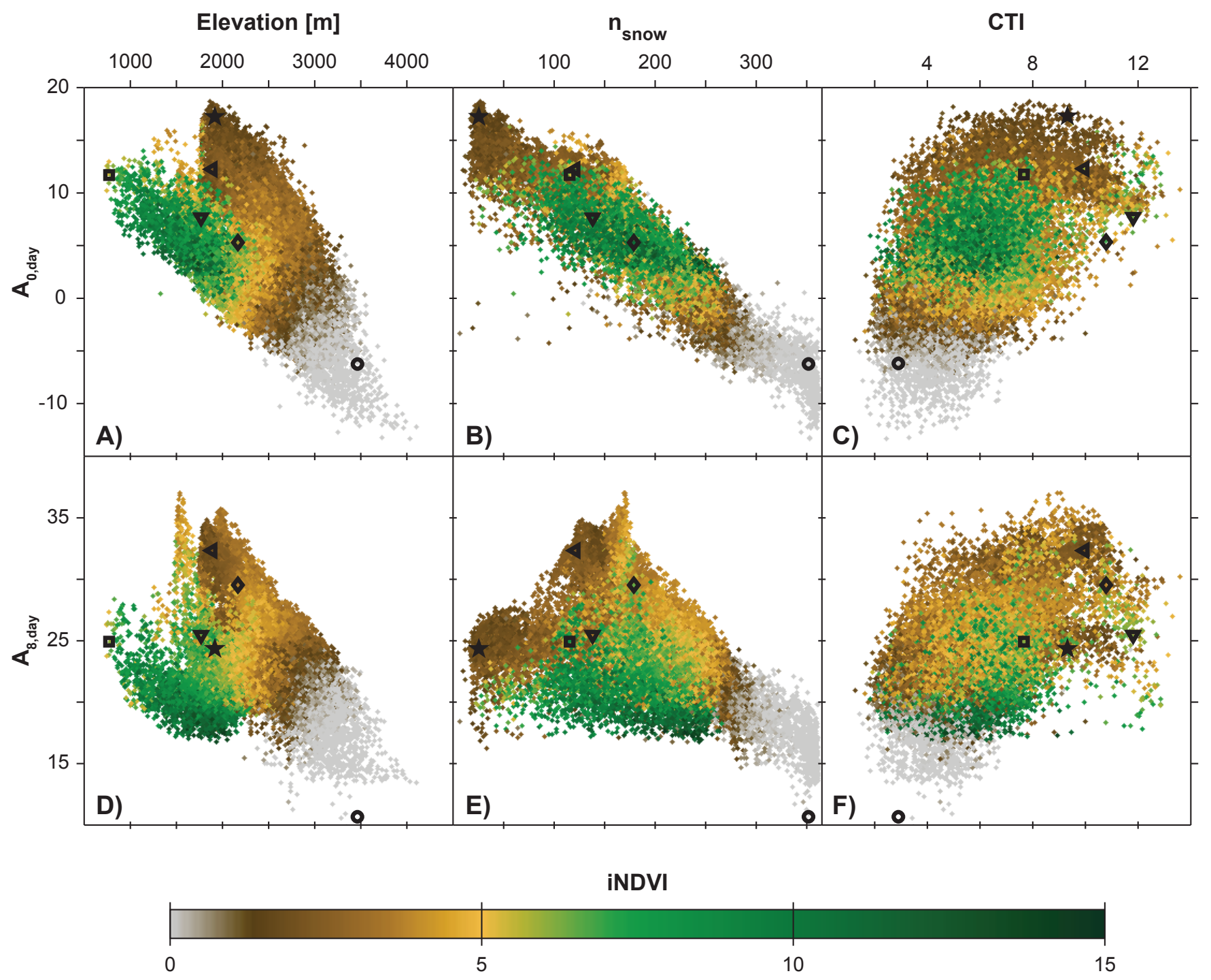

Figure 7: Scatterplots between the amplitudes of the principal Fourier components, and the physiographic variables for $L S T_{d a y}$. The values of the pixels represented in Fig. 5 are marked by their corresponding symbols. 


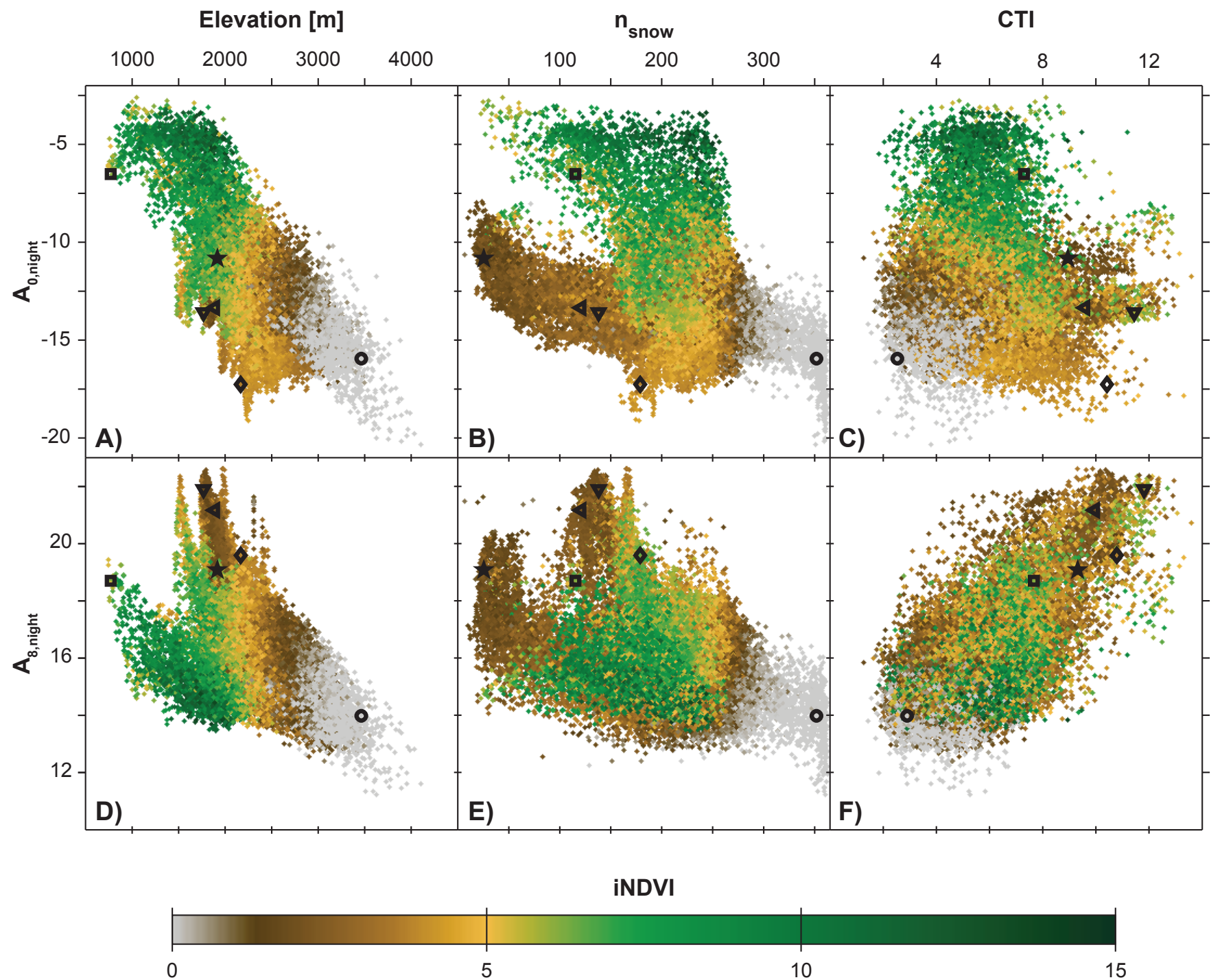

Figure 8: Scatterplots between the amplitudes of the principal Fourier components, and the physiographic variables for $L S T_{\text {night }}$. The values of the pixels represented in Fig. 5 are marked by their corresponding symbols. 


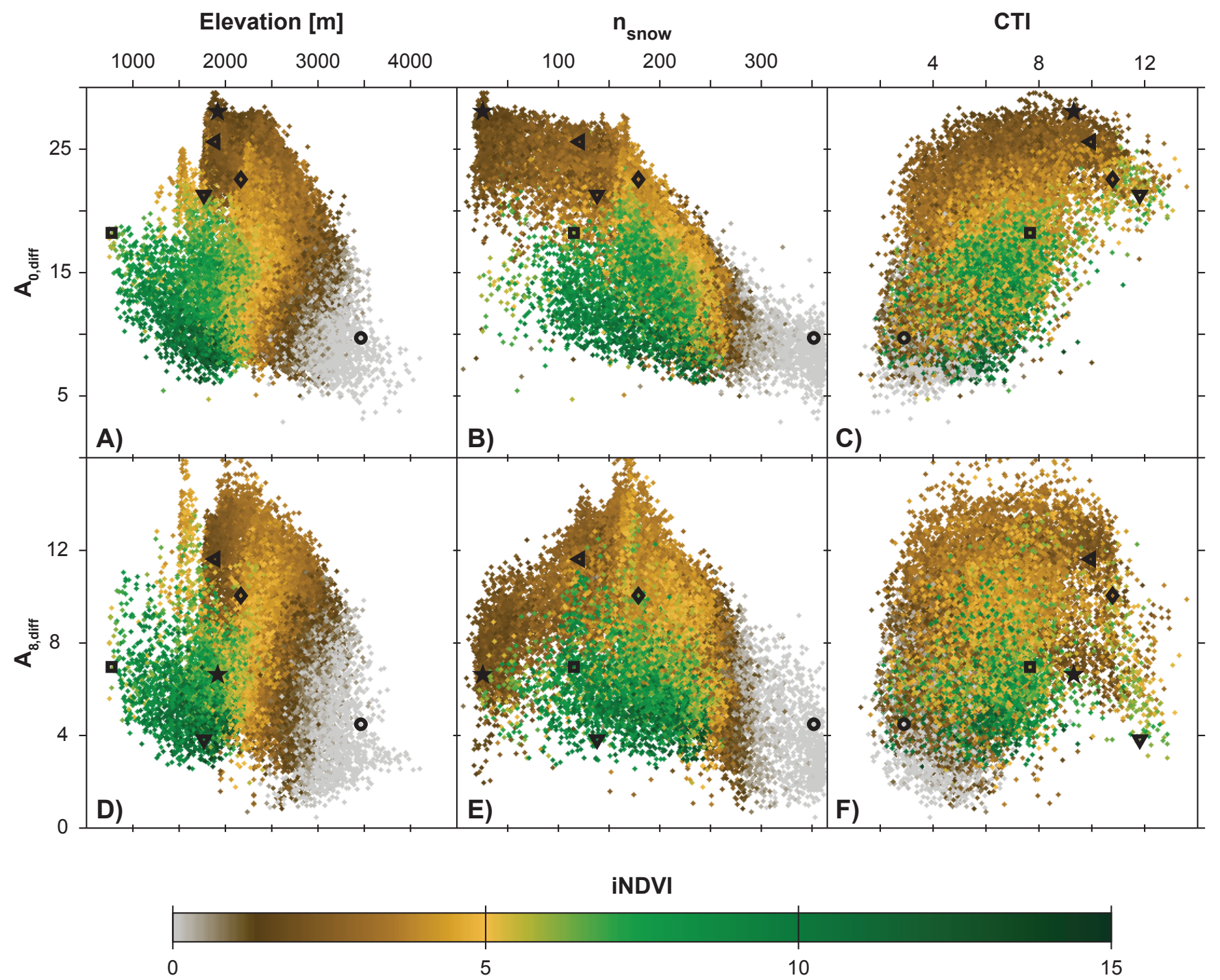

Figure 9: Scatterplots between the amplitudes of the principal Fourier components, and the physiographic variables for $L S T_{d i f f}$. The values of the pixels represented in Fig. 5 are marked by their corresponding symbols. 


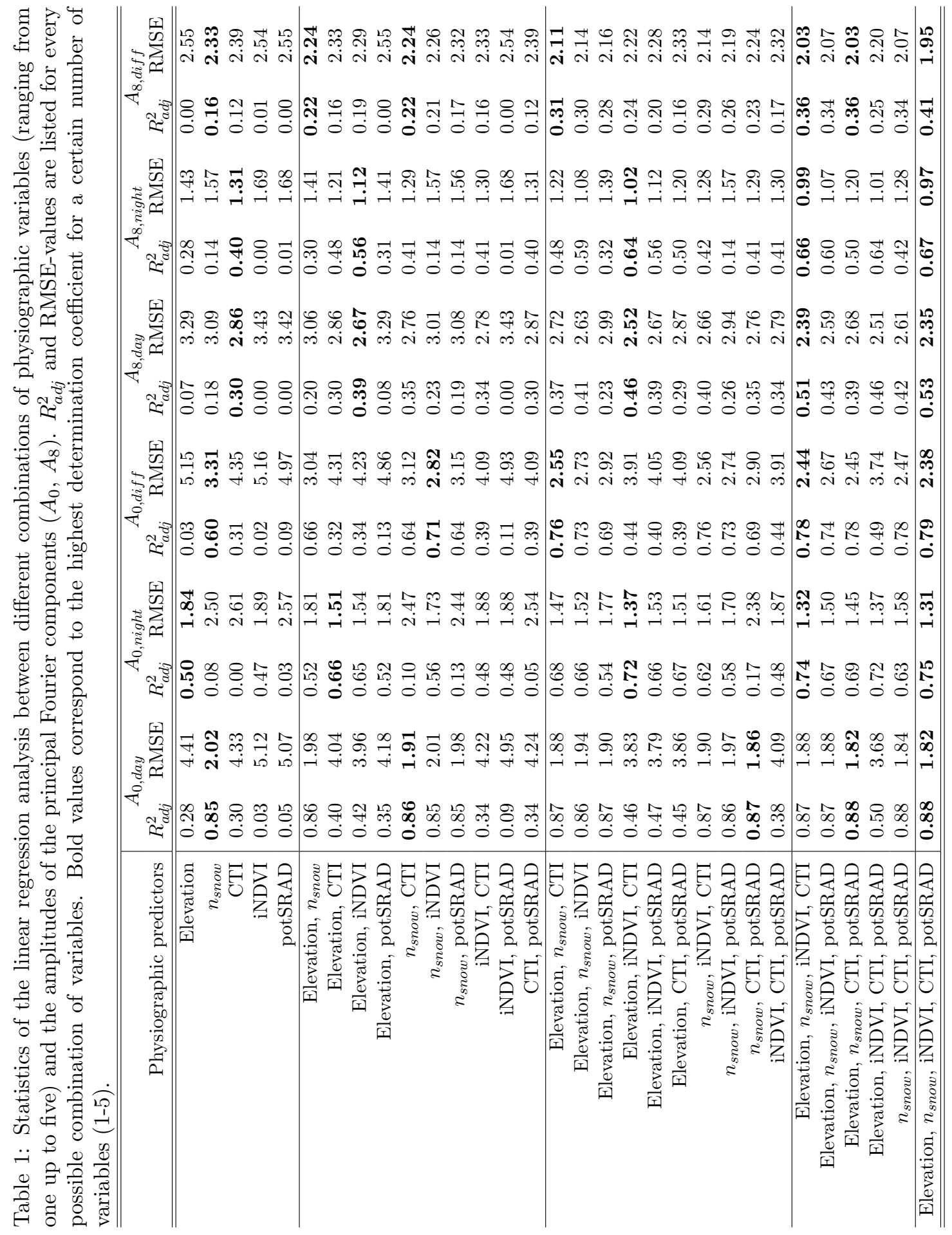

